\title{
Florestas de restinga e de terras baixas na planície costeira do sudeste do Brasil: vegetação e heterogeneidade ambiental
}

\author{
Marco Antonio Assis ${ }^{1}$, Eduardo Magalhães Borges Prata ${ }^{1}$, Fernando Pedroni², Maryland Sanchez ${ }^{2}$, \\ Pedro Vasconcellos Eisenlohr ${ }^{3,8}$, Fernando Roberto Martins ${ }^{3}$, Flavio Antonio Maës dos Santos ${ }^{3}$, \\ Jorge Yoshio Tamashiro ${ }^{3}$, Luciana Ferreira Alves ${ }^{4}$, Simone Aparecida Vieira ${ }^{5}$, Marisa de Cássia Piccolo ${ }^{5}$, \\ Susian Christian Martins 5 , Plínio Barbosa de Camargo ${ }^{5}$, Janaina Braga do Carmo ${ }^{6}$, \\ Eliane Simões ${ }^{7}$, Luiz, Antonio Martinelli ${ }^{5}$ \& Carlos Alfredo Joly ${ }^{3,8}$ \\ ${ }^{1}$ Departamento de Botânica, Instituto de Biociências de Rio Claro, CP 199, \\ Universidade Estadual Paulista Júlio de Mesquita Filho - UNESP, CEP 13506-900, Rio Claro, SP, Brasil, \\ e-mail:massis@rc.unesp.br; eduardoprata@ymail.com \\ ${ }^{2}$ Departamento de Ciências Biológicas e da Saúde, Universidade Federal de Mato Grosso - UFMT, \\ CEP 78698-000, Pontal do Araguaia, MT, Brasil, e-mail: fpedroni@ufmt.br; maryland@ufmt.br \\ ${ }^{3}$ Departamento de Biologia Vegetal, Instituto de Biologia, \\ Universidade Estadual de Campinas - UNICAMP, CP 6109, CEP 13083-970, Campinas, SP, Brasil, \\ e-mail:pedrov.eisenlohr@gmail.com; fmartins@unicamp.br; \\ fsantos@unicamp.br; tamashi@unicamp.br; cjoly@unicamp.br \\ ${ }^{4}$ Instituto de Botânica, São Paulo, SP, Brasil, Institute of Arctic and Alpine Research - INSTAAR, \\ Campus Box 450, University of Colorado, Boulder CO, USA 80309, e-mail: luciana.alves@ colorado.edu \\ ${ }^{5}$ Laboratório de Ecologia Isotópica/CENA, Universidade de São Paulo - USP, CP 96, \\ e-mails: sivieira@unicamp.br; mpiccolo@cena.usp.br; susian@cena.usp.br; \\ pcamargo@cena.usp.br; martinelli@cena.usp.br \\ ${ }^{6}$ Universidade Federal de São Carlos - UFSCar, Campus Sorocaba, Rodovia João Leme dos Santos, \\ km 110, CEP 18052-780, Sorocaba, SP, Brasil, e-mail: jbcarmo2008@gmail.com \\ ${ }^{7}$ Núcleo Picinguaba, Parque Estadual da Serra do Mar, Secretaria do Estado do Meio Ambiente, \\ Rod. BR 101, Km 8, CP 157, CEP 11680-000, Ubatuba, SP, Brasil, e-mail: licanp@terra.com.br \\ ${ }^{8}$ Autores para correspondência: Pedro V. Eisenlohr, e-mail: pedrov.eisenlohr@gmail.com; \\ Carlos Alfredo Joly, e-mail: cjoly@unicamp.br
}

ASSIS,M.A.,PRATA,E.M.B.,PEDRONI,F.,SANCHEZ,M.,EISENLOHR,P.V.,MARTINS,F.R., SANTOS,F.A.M., TAMASHIRO, J.Y., ALVES, L.F., VIEIRA, S.A., PICCOLO, M.C., MARTINS, S.C., CAMARGO, P.B., CARMO, J.B., SIMÕES, E., MARTINELLI, L.A. \& JOLY, C.A. Restinga and Lowland forests in coastal plain of southeastern Brazil: vegetation and environmental heterogeneity. Biota Neotrop. 11(2): http://www. biotaneotropica.org.br/v11n2/en/abstract?article+bn02111022011

\begin{abstract}
It was evaluated the floristic similarity between two Atlantic Rainforest physiognomies in Brazilian coast area, herein called Restinga and Lowland forests. The hypothesis was that, due the differences in geomorphologic processes, these forests would differ on soil physical and chemical properties, floristic composition, live aboveground biomass and litterfall production. It was sampled 1 ha $(100 \times 100 \mathrm{~m})$ for each site located in Ubatuba, São Paulo state, SE Brazil. Within each hectare it was recorded trees with $\mathrm{DBH}>4.8 \mathrm{~cm}$ in all $10 \times 10 \mathrm{~m}$ contiguous plots, and collected soil and litterfall samples. The cluster and ordination analyses indicated the two communities as distinct groups considering soil and floristic composition, agreeing with the initial hypothesis. Species diversity was higher $(p<0.0001)$ in the Lowland forest $\left(\mathrm{H}^{\prime}=4.00\right.$ nats.individual $\left.{ }^{-1}\right)$ than in the Restinga $\left(\mathrm{H}^{\prime}=3.38\right.$ nats. individual $\left.^{-1}\right)$. However, litterfall production and biomass did not differ $(p>0.05)$ between the two forests. This apparent paradox could be explained assuming that, since different species establish themselves in the Restinga or Lowland forests and find a favorable spectrum of conditions and resources, they would tend to persist and to develop in that place; even so the edaphic conditions differ between the Restinga and Lowland forests, each species could respond in a particular way to these variations, and then both forests could reach similar values of biomass and litterfall production. It is probable that the environmental filter conditioned by soils has being important for the strong floristic segregation between these two forests.
\end{abstract}

Keywords: atlantic forest, biomass, litterfall, multivariate analysis.

ASSIS, M.A., PRATA, E.M.B., PEDRONI, F., SANCHEZ, M., EISENLOHR, P.V., MARTINS, F.R., SANTOS, F.A.M., TAMASHIRO, J.Y., ALVES, L.F., VIEIRA, S.A., PICCOLO, M.C., MARTINS, S.C., CAMARGO, P.B., CARMO, J.B., SIMÕES, E., MARTINELLI, L.A. \& JOLY, C.A. Florestas de restinga e de terras baixas na planície costeira do sudeste do Brasil: vegetação e heterogeneidade ambiental. Biota Neotrop. 11(2): http://www.biotaneotropica.org.br/v11n2/pt/abstract?article+bn02111022011 
Resumo: Foram avaliadas semelhanças florísticas entre duas fisionomias de Floresta Atlântica na região costeira do Brasil, denominadas Floresta de Restinga e Floresta das Terras Baixas. A hipótese era que, devido à diferença nos processos geomorfológicos, essas duas florestas difeririam em variáveis físico-químicas dos solos, composição florística, biomassa aérea e produção de serapilheira. O trabalho foi conduzido em uma área de 1 ha $(100 \times 100 \mathrm{~m})$ em cada tipo de floresta, no município de Ubatuba, São Paulo. Foram registrados e medidos todos os indivíduos arbóreos com DAP $>4,8 \mathrm{~cm}$ e coletadas amostras de solo e serapilheira. As análises de agrupamento e de ordenação indicaram que os solos e principalmente a flora distribuem-se como grupos bem definidos, concordando com a hipótese de distinção entre as duas florestas. A diversidade de espécies foi maior $(p<0.0001)$ na Floresta de Terras Baixas $\left(\mathrm{H}^{\prime}=4,00\right.$ nats.indivíduo $\left.{ }^{-1}\right)$ do que na Restinga $\left(\mathrm{H}^{\prime}=3,38\right.$ nats.indivíduo $\left.{ }^{-1}\right)$. No entanto, a produção de serapilheira e a biomassa não diferiram $(p>0,05)$ entre as duas florestas. Esse aparente paradoxo poderia ser explicado supondo-se que, uma vez que espécies diferentes consigam se estabelecer na Restinga ou nas Terras Baixas e encontrem um espectro favorável de condições e recursos, elas tenderiam a persistir e se desenvolver naquele local; nesse caso, embora as condições edáficas difiram entre as duas áreas, cada espécie responderia de modo particular a essas variações, de modo que as florestas poderiam atingir valores semelhantes de biomassa e produção de serapilheira. É provável que o filtro ambiental condicionado pelos solos esteja sendo importante para a forte separação florística entre essas duas florestas.

Palavras-chave: floresta atlântica, biomassa, serapilheira, análise multivariada.

\section{Introdução}

Na planície costeira do Brasil, há sedimentos predominantemente arenosos que podem ter diferentes origens e feições, como dunas móveis e fixas, terraços marinhos e fluviais, restingas e planícies aluviais ou de inundação (Ponçano et al. 1981). Nessa planície, ocorrem variados tipos de vegetação (campos, escrubes e florestas) que, segundo Rizzini (1997), fazem parte do Complexo da Restinga. $\mathrm{Na}$ literatura, a palavra restinga tem várias acepções. Na acepção geomorfológica restrita, as restingas seriam parte da planície costeira, formadas por sedimentos depositados pelo mar como resultado das transgressões e regressões ocorridas nos oceanos nos últimos milhares de anos, relacionadas a períodos glaciais e interglaciais (Araújo \& Lacerda 1987). Compreendem cordões de areia depositados paralelamente à linha da costa em decorrência da dinâmica construtiva e destrutiva do mar, preenchendo ou tendendo a preencher reentrâncias mais ou menos extensas do litoral (Leinz \& Leonardos 1977, Guerra \& Guerra 1997). Na acepção geomorfológica ampla, a palavra restinga designa de modo geral a planície costeira, em decorrência da enorme dificuldade de distinguir entre as diferentes feições geomorfológicas (terraços marinhos e aluviais, planícies de inundação etc.). Na acepção botânica, as restingas se referem a um grande conjunto de formas de vegetação (Rizzini 1997, Assis et al. 2004).

No Complexo da Restinga, algumas de suas formações são florestais, recebendo por vezes a denominação de "florestas de restinga" (César \& Monteiro 1995). A flora e a estrutura dessas florestas são ainda pouco conhecidas (Cesar \& Monteiro 1995, Lacerda 2001) e menos conhecidas ainda são as relações entre essas florestas e outras também localizadas na Província Costeira (Ponçano et al. 1981), como as florestas situadas no início (sopé) da encosta, classificadas como Floresta Ombrófila Densa (FOD) das Terras Baixas no sistema de Veloso et al. (1991). Entre essas duas fitofisionomias florestais, características como solos, regime hídrico e vegetação comumente se modificam. Porém, ainda não se investigou em que medida solos e vegetação diferem. Considerando uma situação em que essas florestas ocorram geograficamente próximas, uma Floresta de Restinga seria distinta de uma FOD das Terras Baixas? Respostas a esse tipo de questão são úteis para se ampliar o conhecimento sobre a variação e a heterogeneidade florística, estrutural e edáfica da Mata Atlântica, permitindo a formulação de práticas conservacionistas nesse hotspot (Myers et al. 2000).
Para investigar possíveis semelhanças entre uma Floresta na Restinga e outra no início da encosta (aqui denominada genericamente de Terras Baixas), deve-se primeiramente ter claro que a vegetação que cobre qualquer área do planeta é condicionada por três fatores primordiais: clima, solo e histórico de perturbações (Brown \& Lomolino 2006). O clima regional é essencialmente o mesmo entre a Floresta de Restinga e as Terras Baixas na costa sudeste do Brasil. O solo parece ter um papel especial na região litorânea, onde processos erosivos e de sedimentação resultam nos substratos peculiares das planícies costeiras (Villwock 1987). Conforme a região considerada, pode haver sedimentação eólica direta nas baixadas litorâneas mais próximas do mar, ou sedimentação eólica juntamente com sedimentação coluvial nas Terras Baixas (Corrêa et al. 2008). Quanto às perturbações (e ainda considerando os solos), na Restinga pode haver inundações periódicas com água doce ou salobra, que exercem forte papel seletivo, pois poucas espécies arbóreas sobrevivem à saturação hídrica do solo (Oliveira \& Joly 2010). Nas Terras Baixas os deslizamentos da encosta representam mais um mecanismo de formação de clareiras, favorecendo o estabelecimento e a persistência de espécies que dependem destas para germinar (Denslow 1987), o que pode resultar em um aumento da diversidade.

A composição de uma comunidade madura é resultado de processos estocásticos e determinísticos atuando como filtros ou peneiras que selecionariam as espécies capazes de chegar, se estabelecer e persistir em cada ambiente (Ackerly 2003). O filtro da dispersão atua na chegada de propágulos a uma área, enquanto filtros ambientais, como por exemplo o solo, atuam na capacidade de sobrevivência de indivíduos nesta área. Considerando situações nas quais tanto a Restinga quanto as Terras Baixas estariam sob mesmo clima regional, poderia se questionar se as diferenças edáficas entre essas áreas atuariam como filtros, determinando composições florísticas distintas.

Também é importante investigar, numa comparação entre florestas tropicais, a estrutura das comunidades arbóreas considerando indicadores funcionais, pois estes podem contribuir para uma caracterização mais abrangente da vegetação (por exemplo, Chave et al. 2001). Dois importantes indicadores funcionais dos ecossistemas tropicais são a biomassa viva acima do solo e a produção da serapilheira. Estima-se que, nas florestas tropicais, grande parte do carbono esteja estocada na biomassa, representando grande fração da produtividade global (Malhi et al. 1999). Segundo Brunig (1983), a biomassa pode variar de acordo com o solo e a altitude. Por sua vez, a quantidade de serapilheira encontrada no solo depende da relação 
entre a taxa de sua deposição e a velocidade de sua decomposição, a qual é influenciada diretamente por variáveis ambientais como precipitação e temperatura (Spain 1984). Essas variáveis são essencialmente as mesmas entre florestas de Restinga e das Terras Baixas em uma mesma região. Porém, além dessas variáveis, outros fatores condicionam a quantidade de serapilheira que é depositada no solo, dentre os quais altitude, características físico-químicas dos solos, composição florística e estrutura comunitária (Vitousek 1982, Londsdale 1988, Facelli \& Pickett 1991, Sundarapadian \& Swamy 1999), os quais podem variar entre essas duas florestas. Embora o conhecimento sobre a variabilidade da biomassa e da produção de serapilheira nas florestas tropicais venha aumentando nos últimos anos, essas informações em geral não têm sido integradas a outros dados da vegetação, como composição florística e solos.

Considerando diferenças e semelhanças entre dois sítios geograficamente muito próximos na planície costeira, o objetivo deste estudo foi investigar as seguintes expectativas:

- A maior frequência de perturbações sazonais (inundações periódicas) na Restinga e as diferenças físico-químicas dos solos limitariam fortemente o número de espécies capazes de persistir na Restinga, implicando em uma diversidade de espécies menor do que na comunidade das Terras Baixas no Parque Estadual da Serra do Mar (PESM), em Ubatuba, São Paulo; e

- A grande heterogeneidade das condições ambientais entre as diferentes feições da planície costeira representaria filtros que selecionariam espécies diferentes, possivelmente compondo comunidades com características funcionais (biomassa e produção de serapilheira) também distintas, resultando em grande heterogeneidade florística do componente arbóreo entre esses dois tipos de florestas.

Este estudo é parte do Projeto Temático BIOTA Gradiente Funcional - "Composição florística, estrutura e funcionamento da Floresta Ombrófila Densa dos Núcleos Picinguaba e Santa Virgínia do Parque Estadual da Serra do Mar, São Paulo, Brasil" (FAPESP 03/12595-7) (Joly et al. 2008).

\section{Material e Métodos}

\section{1. Áreas de estudo}

Dentro do subgrupo de formações da Floresta Ombrófila Densa, o IBGE (Veloso et al. 1991) reconhece diferentes formações, sendo duas delas a Floresta Ombrófila Densa Aluvial e a Floresta Ombrófila Densa das Terras Baixas. A Floresta Ombrófila Densa Aluvial, um caso especial das florestas ripárias ou ripícolas, ocorre nas planícies aluviais, ao longo dos cursos de água. Nas latitudes meridionais de $16^{\circ}$ a $24^{\circ}$, a Floresta Ombrófila Densa das Terras Baixas ocorre entre 5 e $50 \mathrm{~m}$ de altitude (Veloso et al. 1991). Na planície costeira, em geral é muito difícil distinguir entre essas duas formações em decorrência da semelhança fisionômica entre elas, pois ambas são constituídas por grande abundância de macrofanerófitos, trepadeiras e epífitos (Veloso et al. 1991) e há grande dificuldade de se estabelecer os limites entre a sedimentação aluvial (que constitui a planície aluvial) e os demais tipos de sedimentação e feições geomorfológicas.

As áreas estudadas localizam-se no município de Ubatuba, litoral norte do estado de São Paulo, no interior do Núcleo Picinguaba (aproximadamente $23^{\circ} 20^{\prime} 22^{\prime \prime} \mathrm{S}$ e $44^{\circ} 46^{\prime} 51^{\prime}$ ' O) do Parque Estadual da Serra do Mar (PESM). A Floresta de Restinga (que, no presente caso, enquadra-se na definição de Floresta Ombrófila Densa Aluvial do IBGE) situa-se a aproximadamente $10 \mathrm{~m}$ de altitude, na Praia da Fazenda, onde deságuam os principais rios da região, o Rio da Fazenda e o Rio Picinguaba (Lacerda 2001). Nesse sítio, o solo é submetido, sazonalmente, à saturação hídrica, sendo habitual que entre dezembro e março o lençol freático esteja até $0,5 \mathrm{~m}$ acima do solo (César \& Monteiro 1995). As Terras Baixas, por sua vez, situam-se próximas aos $50 \mathrm{~m}$ de altitude e encontram-se ao longo da Trilha do Corisco, que sai da Casa da Farinha em direção a Paraty, RJ. Essas duas florestas distam cerca de $3 \mathrm{~km}$ entre si.

\section{Coleta e processamento dos dados}

\subsection{Solos}

Os dados de solo foram obtidos do trabalho de Martins (2010), que coletou sistematicamente 16 amostras em cada floresta (Restinga e Terras Baixas), nas profundidades $0-5 ; 5-10 ; 10-20 ; 20-30 ; 30$ 40; 40-50; 50-75 e 75-100 cm. Para cada uma das profundidades e horizontes, foram obtidos valores para variáveis químicas $(\mathrm{Ca}, \mathrm{Mg}, \mathrm{P}$, K, Al, S, Na, Capacidade de Troca Catiônica - CTC, Soma de Bases - SB, Saturação por Bases - V\% e Saturação por Alumínio - m\%) e físicas (areia, silte e argila).

\subsection{Florística e diversidade}

Os procedimentos de campo para a implantação das parcelas e a realização do inventário florestal foram baseados em protocolos largamente utilizados em florestas tropicais (Clark 2002, Phillips \& Baker 2002) e estão descritos detalhadamente em Joly et al. (2008). Em cada área foram amostradas todas as árvores, palmeiras e pteridófitas vivas com DAP (diâmetro do caule à altura do peito) $\geq 4,8 \mathrm{~cm}$, dentro de um bloco de 1 ha $(100 \times 100 \mathrm{~m})$, subdividido em 100 parcelas contíguas de $10 \times 10 \mathrm{~m}$. Foram coletados ramos férteis ou estéreis para identificação taxonômica, realizada por especialistas. Os táxons foram classificados quanto às famílias segundo a proposta do APG II (2003) para as angiospermas e de Smith et al. (2006) para as pteridófitas. A nomenclatura dos binômios e de suas respectivas autoridades foi padronizada de acordo com o banco de dados "W3 Trópicos" do Missouri Botanical Garden - MOBOT (2008).

\subsection{Biomassa viva acima do solo e produção de serapilheira}

Foram utilizados os dados de Alves et al. (2010) e de Vieira et al. (2008) para comparar as médias de biomassa por parcela entre a Floresta de Restinga e as Terras Baixas. A biomassa viva aérea das árvores foi estimada segundo o modelo alométrico que utiliza dados de DAP, altura e densidade da madeira gerados no inventário florestal, desenvolvido por Chave et al. (2005) para florestas tropicais úmidas. Para estimar a biomassa de palmeiras, foi utilizado o modelo proposto por Hughes (1997 apud Nascimento \& Laurance 2002) e, para pteridófitas, o modelo proposto por Tiepolo et al. (2002).

Para a comparação da produção de serapilheira entre as duas áreas, foram utilizados os dados apresentados por Sousa-Neto et al. (2011). Para amostrar a serapilheira foram distribuídos aleatoriamente, em cada bloco de 1 ha, 30 coletores circulares de $0,29 \mathrm{~m}^{2}$ dispostos a $50 \mathrm{~cm}$ acima da superfície do solo. A aleatoriedade foi conseguida a partir de sorteios de 30 parcelas dentre as 100 parcelas de cada floresta. Em intervalos de 15 dias entre maio/2007 e abril/2008, o material interceptado pelos coletores foi recolhido regularmente em sacos de papel etiquetados. No laboratório, a serapilheira coletada foi submetida à secagem prévia e à separação manual nas frações: folhas, flores/frutos/sementes, galhos com até $2 \mathrm{~cm}$ de diâmetro e demais componentes (miscelânea). Após a triagem, as frações foram acondicionadas em sacos de papel, etiquetados e levados para secagem em estufa a $60^{\circ} \mathrm{C}$, até peso constante. As médias de deposição da serapilheira total e de suas frações foram calculadas por coletor e os valores foram expressos em t.ha-1. 


\section{Análises numéricas}

Nos testes estatísticos (adiante), variáveis cujos dados não eram normalmente distribuídos (teste de D'Agostino-Pearson) ou que não apresentassem homogeneidade de variâncias (teste de Bartlett) foram transformados logaritmicamente (logaritmo natural). Quando necessário, amostras com valores extremos (outliers) foram removidas. O teste U de Mann-Whitney foi utilizado como alternativa ao teste $t$ nos casos de não-normalidade e/ou heterogeneidade de variâncias (Zar 1999). Os resultados dos testes estatísticos apresentados nas tabelas consideram apenas os dados em sua forma final, ou seja, transformados quando necessário e sem eventuais outliers. Esses testes foram feitos no programa BioEstat versão 5.0 (Ayres et al. 2007) e em todos eles adotamos nível de significância $(\alpha)$ de $5 \%$.

As análises multivariadas (abaixo) foram processadas no FITOPAC versão 2 (Shepherd 2008), a menos que dito de outra forma.

\subsection{Solos}

Foi organizada uma matriz em que uma variável geral (fósforo, potássio, $\mathrm{pH}$ etc.) associada a uma profundidade (0-10, 10-20, 20$30,30-40,40-50,50-75$ ou $75-100 \mathrm{~cm}$ ) foi considerada um descritor (ex: fósforo 0-10) de cada objeto (amostra). Essa matriz foi usada nas análises a seguir.

Para detectar a formação ou não de grupos das amostras de solo, foi utilizada a análise de agrupamento aglomerativa (Sneath \& Sokal 1973) mediante UPGMA (Associação Média não-ponderada). Esse algoritmo também foi utilizado nas demais análises de agrupamento deste trabalho. O coeficiente de distância de Bray-Curtis foi escolhido para essa etapa. Obteve-se o coeficiente de correlação cofenética, que permite avaliar se o dendrograma gerado sofreu distorção acentuada (< $0,7)$ em relação à similaridade real entre cada par de parcelas. O método PCO (Análise de Coordenadas Principais) foi utilizado de forma complementar, com o objetivo de detectar uma possível formação de blocos ao longo do gradiente investigado, o que estaria de acordo com a hipótese de distinção entre as duas florestas (Restinga e Terras Baixas).

Para evidenciar o nível de proximidade das variáveis em relação às amostras foi utilizado o gráfico "biplot" da CA (Análise de Correspondência), um método que ordena descritores e objetos simultaneamente. A CA foi processada após serem eliminadas as variáveis redundantes, detectadas nas análises prévias e confirmadas por testes de correlação de Pearson (Zar 1999). A escolha de qual variável seria removida em cada conjunto de redundâncias foi feita com base na análise da dimensão de equilíbrio dos autovetores para os dois principais eixos da PCA (Análise de Componentes Principais).

Uma nova verificação de redundâncias foi feita apenas para as variáveis gerais de solos (isto é, desconsiderando as profundidades), para que fossem selecionadas as variáveis para os testes de comparação de médias/medianas entre as duas florestas. Para comparar a CTC entre as duas florestas, foi utilizado o teste $t$. Para $\mathrm{pH} \mathrm{em} \mathrm{CaCl}_{2}, \mathrm{SB}$, $\mathrm{V} \%$ e $\mathrm{m} \%$, foi efetuado o teste U de Mann-Whitney.

\subsection{Florística e diversidade}

A diversidade estimada em cada área foi comparada de duas formas. Primeiro, foi estimada a riqueza de espécies de cada área pelo método Jackknife de primeira ordem (Smith \& van Belle 1984) no programa EstimateS versão 8.2 (Colwell 2009), construindo um diagrama mostrando os valores médios acumulados por parcela e seus respectivos desvios-padrão. Depois, a diversidade de Shannon (H') foi comparada entre as duas áreas, utilizando o teste $t$ modificado descrito por Poole (1974), no programa PAST versão 1.79 (Hammer et al. 2001).

Foram construídas duas matrizes (binária e quantitativa) para as demais análises florísticas. Na matriz binária foram inseridos os valores zero ou um (ausência ou presença, respectivamente) e na matriz quantitativa, o número de indivíduos amostrados de cada espécie em cada parcela. A aplicação da análise de outliers (McCune \& Grace 2002) detectou 10 parcelas na matriz binária e 14 parcelas na matriz quantitativa. Estas parcelas foram eliminadas porque poderiam afetar os padrões gerais e causar ruídos (McCune \& Grace 2002). Para esta análise foi utilizado o software PC-ORD versão 4.0 (McCune \& Mefford 1999), adotando-se o nível de corte de dois desvios-padrão. Foram eliminadas ainda as espécies ocorrentes em apenas uma parcela e, no caso da matriz quantitativa, espécies representadas por menos de cinco indivíduos no total, pois estas tendem a contribuir de forma insignificante para a variância total nos dados, além de aumentarem a chance de erros de interpretação (Gauch Jr. 1982). Com estes procedimentos obteve-se uma matriz binária final de 131 espécies (colunas) e 190 parcelas (linhas) e uma matriz quantitativa final de 88 espécies e 186 parcelas.

Análises de agrupamento foram efetuadas para averiguar as relações de similaridade florística entre as parcelas. Novamente o coeficiente de correlação cofenética foi obtido. Foram aplicados o coeficiente de Jaccard para matriz binária e o coeficiente de distância de Bray-Curtis para a matriz quantitativa. Como método de ordenação, foi utilizada a PCO (Análise de Coordenadas Principais), objetivando dispor as amostras ao longo de eixos representativos da variabilidade indicada pela ocorrência e abundância das espécies e, assim, checar a existência de gradientes ou blocos florísticos. Com base inicialmente na matriz binária, foi gerada a PCO utilizando dois coeficientes diferentes: Jaccard e distância euclidiana simples. $\mathrm{O}$ padrão encontrado foi o mesmo, mas com a distância euclidiana simples a explicação dos primeiros eixos para a variância total dos dados foi superior, razão pela qual esse coeficiente foi preferido. O mesmo ocorreu com a PCO da matriz quantitativa, utilizando inicialmente o coeficiente de Bray-Curtis e, em seguida, a distância euclidiana simples.

Por meio da TWINSPAN - Two-Way Indicator Species Analysis (Hill 1979) foram obtidas espécies indicadoras dos grupos gerados nos dois sítios, a partir de um processo de sucessivas dicotomizações, tanto a partir da matriz binária quanto da matriz quantitativa. Os níveis de corte das pseudoespécies (Valentin 2000) para a matriz quantitativa seguiram o default (0-2-5-10-20) do Twinspan for Windows versão 2.3 (Hill \& Smilauer 2005).

Os resultados obtidos para as duas áreas estudadas foram comparados com outras áreas amostradas em cotas altitudinais semelhantes para verificar o nível de similaridade florística entre esses levantamentos. Para isso foi novamente utilizado o método de análise de agrupamento usando-se o coeficiente de Jaccard. Para estas comparações foram selecionados levantamentos fitossociológicos e florísticos publicados que tivessem utilizado o método de parcelas, incluído indivíduos com tamanho mínimo semelhante ao utilizado neste trabalho e que tivessem disponibilizado informações como área total amostrada e fisionomia na qual foi efetuado o estudo.

\subsection{Biomassa viva acima do solo e produção de serapilheira}

Entre a Floresta de Restinga e as Terras Baixas, a biomassa viva acima do solo foi comparada pelo teste U de Mann-Whitney e a produção de serapilheira, pelo teste $t$. 


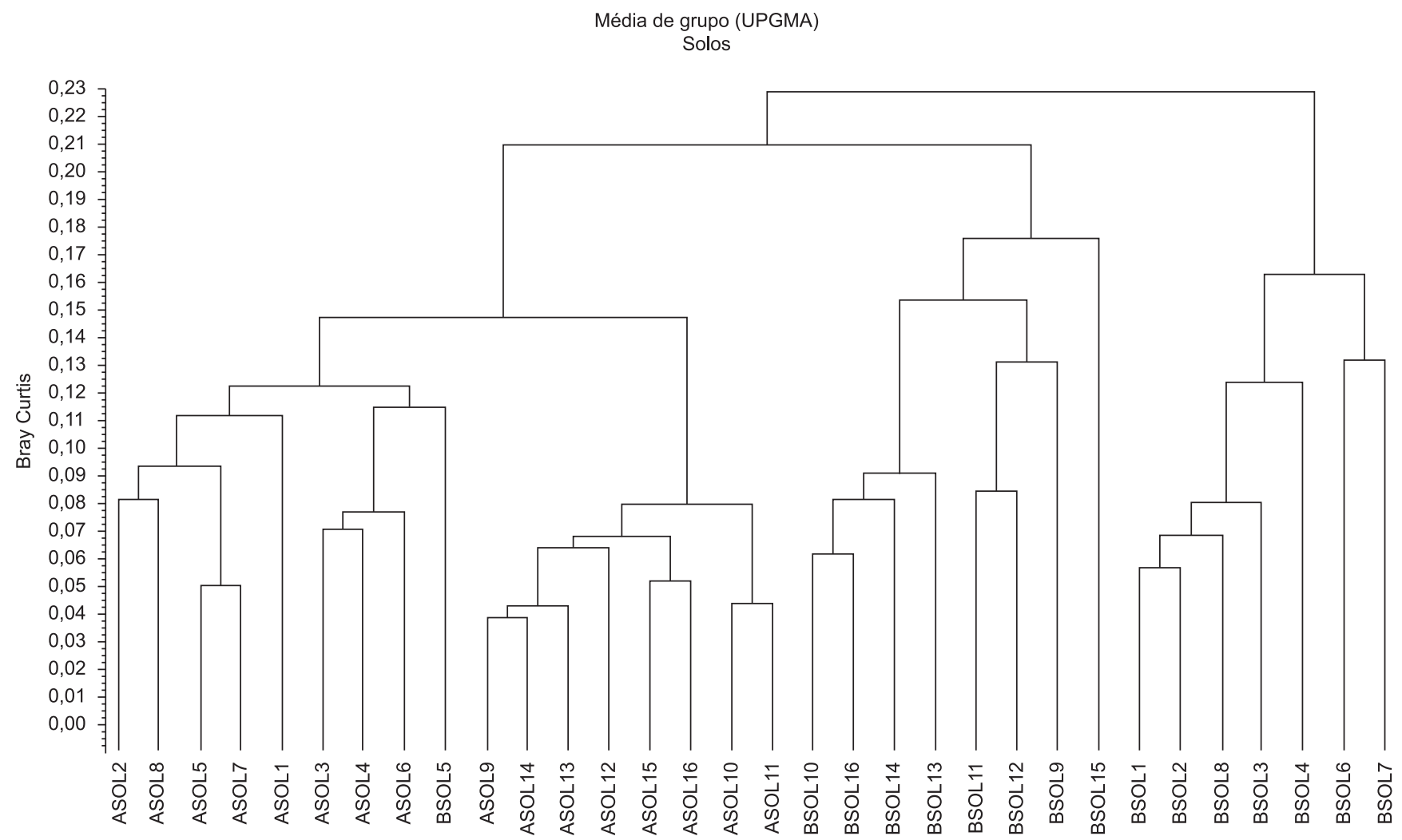

Figura 1. Análise de Agrupamento utilizando o método UPGMA para os dados de solos coletados nas florestas de Restinga (amostras ASOL) e das Terras Baixas (amostras BSOL) do Núcleo Picinguaba, Ubatuba, São Paulo, Brasil.

Figure 1. Cluster analysis using UPGMA method for soils data collected in the Restinga (ASOL samples) and Lowland (BSOL samples) forests at Núcleo Picinguaba/Serra do Mar State Park, Ubatuba, Sao Paulo, Brazil.

\section{Resultados}

\section{Solos}

No nível de 0,22 da distância de Bray-Curtis, formaram-se dois grandes grupos na UPGMA (Figura 1): um contendo apenas amostras de solos das Terras Baixas (na figura, BSOL), mais à direita, e outro, contendo amostras da Floresta de Restinga (ASOL) e das Terras Baixas (BSOL). No nível de 0,20, este segundo grupo subdividiu-se em dois subgrupos, os quais distinguiram claramente as duas florestas, exceto pela presença da amostra BSOL5 no grupo da Floresta de Restinga. O coeficiente de correlação cofenética ( $\mathrm{r}$ cofenética) foi de 0,7170 .

$\mathrm{Na}$ análise PCO (Figura 2), o primeiro eixo explicou 40,78\% da variância total e separou grande parte das amostras da Floresta de Restinga (lado negativo) das amostras das Terras Baixas (lado positivo), exceto ASOL4 e ASOL3 (Restinga), que se posicionaram no lado positivo, e BSOL16 (Terras Baixas), que permaneceu no lado negativo. Essas três amostras aparecem, contudo, próximas ao centro do eixo. O segundo eixo (Figura 2), que representou $27,10 \%$ da explicação total, indicou grande mistura entre as amostras das duas florestas.

Na ordenação por CA (Figura 3), as amostras da Floresta de Restinga se posicionaram no lado negativo e as das Terras Baixas, no lado positivo do primeiro eixo, que explicou 47,32\% da variância total. Esse eixo também indicou tendências opostas dos descritores edáficos: no lado positivo, aparecem em geral as amostras de maior fertilidade (maior associação com carbono, Capacidade de Troca Catiônica - CTC e nutrientes) e no lado negativo, as amostras associadas com variação do $\mathrm{pH}$ e maior saturação por alumínio (m\%). O eixo 2 (Figura 3) explicou 26,6\% da variância total e não indicou distinções fortes entre amostras da Restinga e das Terras Baixas. Esse eixo separou, na parte positiva, algumas amostras com maior associação com magnésio, Saturação por Bases (V\%) e Soma de Bases (SB) e, na parte negativa, as amostras com maior CTC.

Os parâmetros sintéticos e a análise granulométrica dos solos são apresentados na Tabela 1. Os testes mostraram que teor de alumínio, Soma de Bases, CTC e m\% diferiram significativamente entre as duas áreas (Floresta de Restinga e Terras Baixas; Tabela 2).

\section{Florística e diversidade}

Foram amostradas 185 espécies pertencentes a 114 gêneros e 45 famílias (Tabela 3). Do total de espécies, 31 (17\%) foram comuns às comunidades da Restinga e das Terras Baixas, indicando baixa similaridade florística entre essas duas comunidades. Dentre as espécies que apresentaram cinco ou mais indivíduos em cada comunidade, Euterpe edulis foi a espécie comum mais abundante, seguida de Guapira opposita, Garcinia gardneriana, Marlierea tomentosa, Sloanea guianensis e Eugenia fusca (Tabela 3). As demais espécies comuns apresentaram alta abundância em uma comunidade e ocorreram com apenas um ou poucos indivíduos na outra comunidade. Na Floresta de Restinga foram amostradas 84 espécies, 61 gêneros e 32 famílias (Tabela 3), sendo Myrtaceae a família mais rica em espécies (21 espécies, 25\% do total), seguida por Fabaceae (oito espécies, 9,52\% do total). Nas Terras Baixas foram amostradas 137 espécies, 85 gêneros e 38 famílias (Tabela 3), das quais Myrtaceae, com 21 espécies, deteve 22,63\% da riqueza total, seguida por Rubiaceae (14 espécies, 10,22\%). 
Tabela 1. Parâmetros sintéticos e análise granulométrica das amostras de solos coletadas nas florestas de Restinga (FR) e das Terras Baixas (FT) no Núcleo Picinguaba, Ubatuba, São Paulo, Brasil. SB: Soma de Bases; CTC: Capacidade de Troca Catiônica; V\%: saturação por bases; $m \%$ : saturação por alumínio.

Table 1. Synthetic parameters and particle size analysis of soil samples collected in Restinga (RF) and Lowland (FT) forests at Núcleo Picinguaba/ Serra do Mar State Park, Ubatuba, Sao Paulo, Brazil. SB: Sum of bases, CEC: Cation Exchange Capacity, \% V: base saturation; m\%: Al saturation.

\begin{tabular}{|c|c|c|c|}
\hline Parâmetro & Profundidade $(\mathrm{cm})$ & FR & FT \\
\hline \multirow[t]{8}{*}{$\mathrm{pH} \mathrm{CaCl} 2$} & $0-5$ & 3,39 & 3,67 \\
\hline & $5-10$ & 3,46 & 3,60 \\
\hline & $10-20$ & 3,73 & 3,69 \\
\hline & $20-30$ & 3,97 & 3,83 \\
\hline & $30-40$ & 4,09 & 3,93 \\
\hline & $40-50$ & 4,14 & 4,01 \\
\hline & $50-75$ & 4,17 & 4,10 \\
\hline & $75-100$ & 4,16 & 4,17 \\
\hline \multirow[t]{8}{*}{ SB (mmolc.kg-1) } & $0-5$ & 3,49 & 12,32 \\
\hline & $5-10$ & 2,31 & 7,50 \\
\hline & $10-20$ & 2,27 & 4,22 \\
\hline & $20-30$ & 1,89 & 2,30 \\
\hline & $30-40$ & 1,53 & 1,68 \\
\hline & $40-50$ & 1,53 & 1,54 \\
\hline & $50-75$ & 1,48 & 1,45 \\
\hline & $75-100$ & 1,35 & 2,94 \\
\hline \multirow[t]{8}{*}{ CTC (mmol.kg $\left.{ }^{-1}\right)$} & $0-5$ & 110,87 & 140,82 \\
\hline & $5-10$ & 104,50 & 86,50 \\
\hline & $10-20$ & 74,34 & 102,41 \\
\hline & $20-30$ & 49,70 & 70,43 \\
\hline & $30-40$ & 35,72 & 60,93 \\
\hline & $40-50$ & 28,78 & 53,10 \\
\hline & $50-75$ & 22,66 & 50,20 \\
\hline & $75-100$ & 17,91 & 51,54 \\
\hline \multirow[t]{8}{*}{$\mathrm{V}(\%)$} & $0-5$ & 3,58 & 10,60 \\
\hline & $5-10$ & 2,85 & 9,00 \\
\hline & $10-20$ & 3,58 & 4,99 \\
\hline & $20-30$ & 4,65 & 3,82 \\
\hline & $30-40$ & 5,17 & 3,37 \\
\hline & $40-50$ & 6,44 & 3,43 \\
\hline & $50-75$ & 7,80 & 3,38 \\
\hline & $75-100$ & 9,07 & 6,06 \\
\hline \multirow[t]{8}{*}{$\mathrm{m}(\%)$} & $0-5$ & 81,56 & 54,25 \\
\hline & $5-10$ & 86,14 & 67,00 \\
\hline & $10-20$ & 83,39 & 75,21 \\
\hline & $20-30$ & 79,65 & 79,92 \\
\hline & $30-40$ & 80,51 & 81,87 \\
\hline & $40-50$ & 78,74 & 81,63 \\
\hline & $50-75$ & 78,20 & 81,46 \\
\hline & 75-100 & 81,80 & 75,22 \\
\hline Areia $(\%)$ & - & 88,14 & 48,48 \\
\hline Argila (\%) & - & 6,05 & 40,90 \\
\hline Silte $(\%)$ & - & 5,81 & 10,62 \\
\hline
\end{tabular}

A riqueza estimada (Jackknife 1) foi maior nas Terras Baixas, onde a curva de acumulação de espécies mostrou menor tendência à estabilização (Figura 4). A diversidade de Shannon $\left(H^{\prime}\right)$ também foi significativamente maior $(p<0,0001)$ nas Terras Baixas $\left(H^{\prime}=4,00\right.$ nats.indivíduo $\left.{ }^{-1}\right)$ do que na Floresta de Restinga $\left(\mathrm{H}^{\prime}=3,38\right.$ nats.indivíduo $\left.{ }^{-1}\right)$ pelo teste $t$ modificado.

No nível de aproximadamente 0,05 na escala de Jaccard, o dendrograma obtido a partir da matriz florística binária ( $r$ cofenética $=0,8224$ ) evidenciou uma separação em dois grandes grupos, cada um formado apenas por parcelas de uma das florestas (Figura 5). Antes dessa divisão, porém, uma parcela das Terras Baixas (B19) formou um grupo à parte de todas as outras parcelas (Figura 5). A partir da matriz quantitativa, no nível de fusão acima de 0,9 na escala de distância de Bray-Curtis ( $\mathrm{r}$ cofenética $=0,7673$ ), também houve grande separação entre as parcelas das duas florestas (Figura 6).

O primeiro eixo da PCO binária, que explicou $16,14 \%$ da variância total, separou as parcelas da Floresta de Restinga à direita e as das Terras Baixas à esquerda, ao passo que o segundo eixo explicou $5,23 \%$ da variância total e indicou um gradiente interno entre as parcelas da Restinga (Figura 7). O primeiro eixo da PCO quantitativa explicou $21,41 \%$ da variância total e também separou consistentemente as parcelas das duas florestas; o segundo eixo, por sua vez, explicou $12,39 \%$ da variância dos dados e mostrou um gradiente interno entre as parcelas da Floresta de Restinga e a formação de blocos com abundâncias distintas entre as parcelas das Terras Baixas (Figura 8).

A primeira divisão da TWINSPAN, com autovalores de 0,77 para a matriz binária e 0,76 para a matriz quantitativa (valores expressivos, segundo Felfili \& Rezende 2003), forneceu, como espécies indicadoras da Floresta de Restinga, Pera glabrata (Euphorbiaceae), Myrcia racemosa (Myrtaceae), Jacaranda puberula (Bignoniaceae) e Myrcia brasiliensis (Myrtaceae), e para as Terras Baixas, Mollinedia schottiana (Monimiaceae) e Rustia formosa (Rubiaceae). Todas essas, exceto Rustia formosa (indicadora apenas da TWINSPAN binária), foram comuns aos dois conjuntos de dados (binários e quantitativos).

A análise do dendrograma de similaridade com outros levantamentos (os quais são indicados na Tabela 4) indicou que a similaridade geral entre as amostras comparadas foi muito baixa (Figura 9). Note, ao nível de aproximadamente 0,05 na escala de Jaccard, que as Florestas de Restinga de Viamão-RS e de Setiba-ES foram as que menos se assemelharam aos outros levantamentos (Figura 9). As localidades restantes formaram dois grupos no nível de aproximadamente 0,1 de similaridade: um formado por três sítios de encosta próximos entre si, no Rio de Janeiro, e outro formado pelas duas áreas deste estudo (REST-FRS e ENCST-FTB) e por outras duas florestas de encosta e uma de restinga (Figura 9). O grupo com maior similaridade foi aquele formado por duas florestas de encosta do Rio de Janeiro (ENCST-Fragm.II/RJ e ENCST-Fragm.III/RJ), com cerca de 0,45 de similaridade de Jaccard (Figura 9). O coeficiente de correlação cofenética foi de 0,9776 .

\section{Biomassa viva acima do solo e produção de serapilheira}

A biomassa viva total (árvores, palmeiras e pteridófitas) acima do solo foi de 166,3 t.ha ${ }^{-1}$ na Floresta de Restinga e de 218,08 t.ha-1 nas Terras Baixas (para detalhes, ver Alves et al. 2010). Não houve diferença significativa entre as duas áreas (teste U de Mann Whitney, valor- $p=0,14)$.

A produção total de serapilheira foi estimada em 7,68 tha ${ }^{-1} \mathrm{ano}^{-1}$ na restinga e em 8,73 t.ha-1 ano ${ }^{-1}$ nas Terras Baixas (Tabelas 5 e 6); (Sousa Neto et al. 2010). As médias de 0,3071 $( \pm 0,1508)$ na Floresta de Restinga e de 0,3491 ( $\pm 0,1733)$ nas Terras Baixas não diferiram significativamente entre as duas áreas (teste $t$, valor- $p=0,19$ ). 
Tabela 2. Médias ( \pm Desvio-Padrão, DP), Medianas, Amplitudes de Variação e resultados dos testes estatísticos para pHCaCl, teor de Alumínio, Soma de Bases (SB), Capacidade de Troca Catiônica (CTC), Saturação por Bases (V\%) e Saturação por Alumínio (m\%) nas florestas de Restinga (FR) e das Terras Baixas (FT) do Parque Estadual da Serra do Mar, Ubatuba, São Paulo, Brasil. Asteriscos na última coluna indicam significância estatística.

Table 2. Means ( \pm Standard Deviation, SD), medians, ranges of variation and results of statistical tests to $\mathrm{pHCaCl}_{2}$, aluminum content, Sum of Bases ( $\mathrm{SB}$ ), Cation Exchange Capacity (CEC), base saturation (V\%) and Aluminum saturation (m\%) in the Restinga (RF) and Lowland (FT) forests at Núcleo Picinguaba/ Serra do Mar State Park, Ubatuba, Sao Paulo, Brazil. Asterisks in the last column indicate statistical significance.

\begin{tabular}{|c|c|c|c|c|}
\hline Variável & Informações estatísticas & FR & FT & Teste de comparação \\
\hline \multirow{4}{*}{$\mathrm{pH} \mathrm{CaCl}{ }_{2}$} & Média ( \pm DP) & $3,8891( \pm 0,3308)$ & $3,8720( \pm 0,3354)$ & - \\
\hline & Mediana & 4,0000 & 3,9000 & - \\
\hline & Valores mínimo - máximo & $3,0000-4,4000$ & $3,1500-5,1000$ & - \\
\hline & valor-p & - & - & 0,1136 \\
\hline \multirow[t]{4}{*}{ Teor de alumínio } & Média ( \pm DP) & $8,8004( \pm 5,2362)$ & $10,1886( \pm 5,8263)$ & - \\
\hline & Mediana & 8 & 9 & - \\
\hline & Valores mínimo - máximo & $1,45-37$ & $0,45-37$ & - \\
\hline & valor-p & - & - & $0,0219 *$ \\
\hline \multirow[t]{4}{*}{ SB (mmolc.kg-1) } & Média ( $\pm \mathrm{DP})$ & $1,9817( \pm 1,2852)$ & $4,1473( \pm 4,9038)$ & - \\
\hline & Mediana & 2,1 & 2,3 & - \\
\hline & Valores mínimo - máximo & $0,0767-8,1$ & $0-23,7$ & - \\
\hline & valor-p & - & - & $0,0004 *$ \\
\hline \multirow[t]{4}{*}{ CTC (mmolc. $\left.\mathrm{kg}^{-1}\right)$} & Média ( \pm DP) & $55,5599( \pm 45,0212)$ & $83,0843( \pm 46,876)$ & - \\
\hline & Mediana & 39,44 & 72,279 & - \\
\hline & Valores mínimo - máximo & $10,1-207$ & $19-256,6135$ & - \\
\hline & valor-p & - & - & $<0,0001 *$ \\
\hline \multirow[t]{4}{*}{$\mathrm{V} \%$} & Média ( $\pm \mathrm{DP})$ & $5,3919( \pm 4,5683)$ & $5,2485( \pm 5,4057)$ & - \\
\hline & Mediana & 4,065 & 4 & - \\
\hline & Valores mínimo - máximo & $0,13-21$ & $0-32$ & - \\
\hline & valor-p & - & - & 0,1852 \\
\hline \multirow[t]{4}{*}{$\mathrm{m} \%$} & Média ( \pm DP) & $81,2463( \pm 10,0166)$ & $75,0862( \pm 19,2419)$ & - \\
\hline & Mediana & 81,0000 & 78,0000 & - \\
\hline & Valores mínimo - máximo & $37,5600-98,6800$ & $8,9902-100,0000$ & - \\
\hline & valor-p & - & - & $0,0191 *$ \\
\hline
\end{tabular}

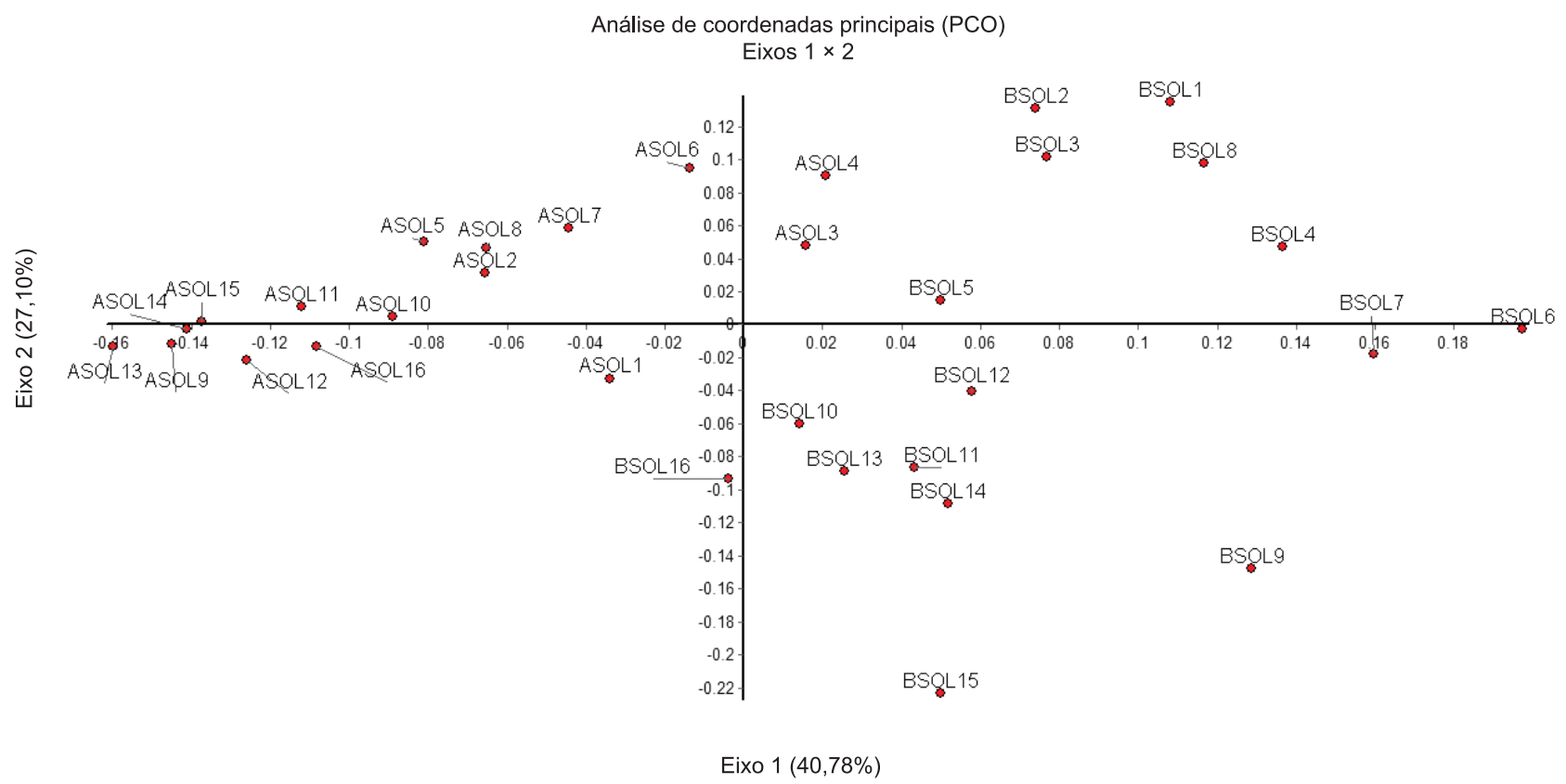

Figura 2. Ordenação por Análise de Coordenadas Principais (PCO) para variáveis de solos das florestas de Restinga (amostras ASOL) e das Terras Baixas (amostras BSOL) do Núcleo Picinguaba, Ubatuba, São Paulo, Brasil.

Figure 2. Ordination by Principal Coordinates Analysis (PCO) for soil variables of the Restinga (ASOL samples) and Lowland (BSOL samples) forests at Núcleo Picinguaba/Serra do Mar State Park, Ubatuba, Sao Paulo, Brazil. 
Assis, M.A. et al.

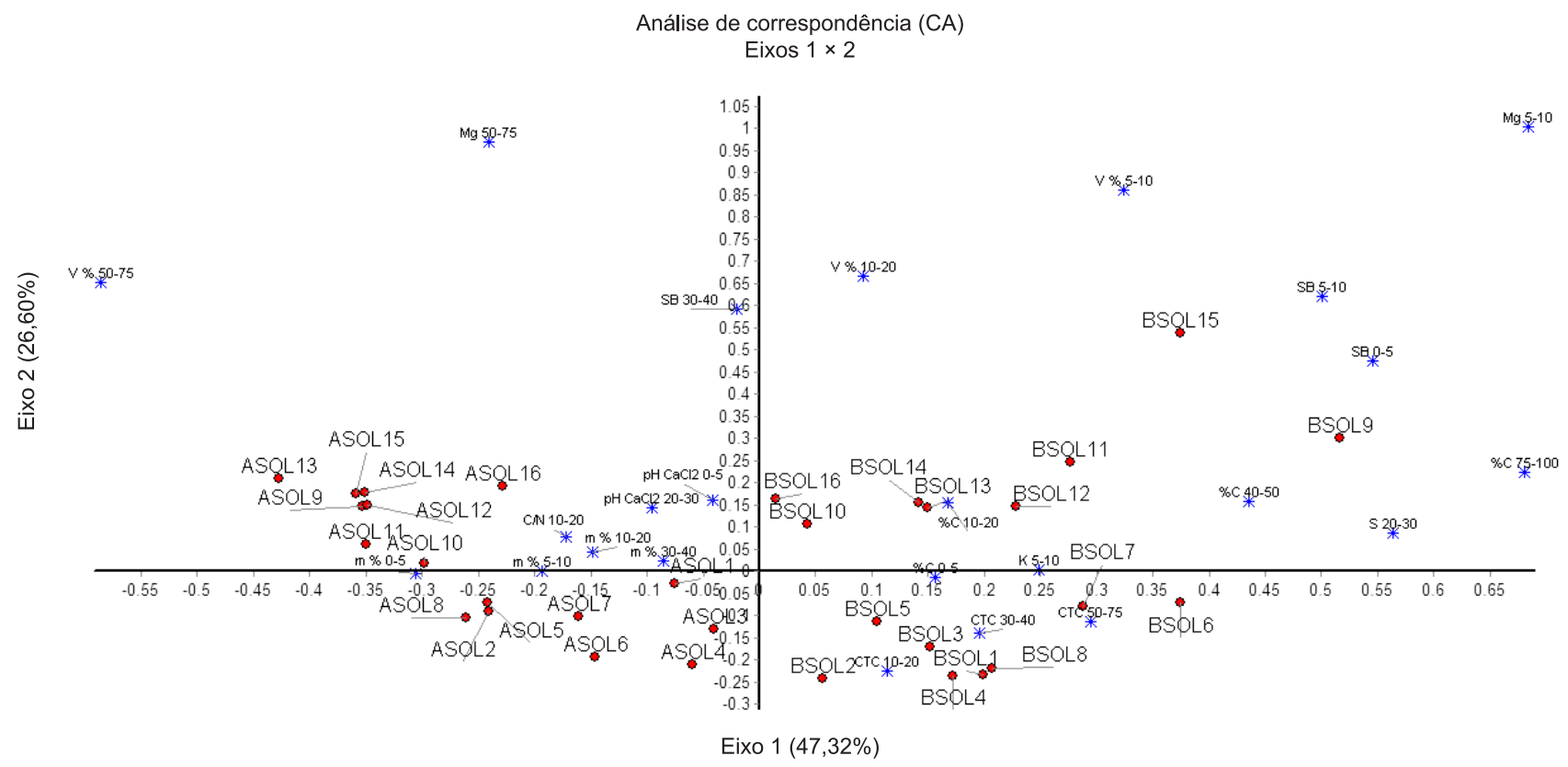

Figura 3. Ordenação “biplot' por Análise de Correspondência (CA) para amostras de solos das florestas de Restinga (amostras ASOL) e das Terras Baixas (amostras BSOL) e variáveis edáficas (asteriscos) do Núcleo Picinguaba, Ubatuba, São Paulo, Brasil.

Figure 3. "Biplot" ordination by Correspondence Analysis (CA) for soil samples of the Restinga (ASOL samples) and Lowland (BSOL samples) forests and soil variables (asterisks) at Núcleo Picinguaba/Serra do Mar State Park, Ubatuba, Sao Paulo, Brazil.

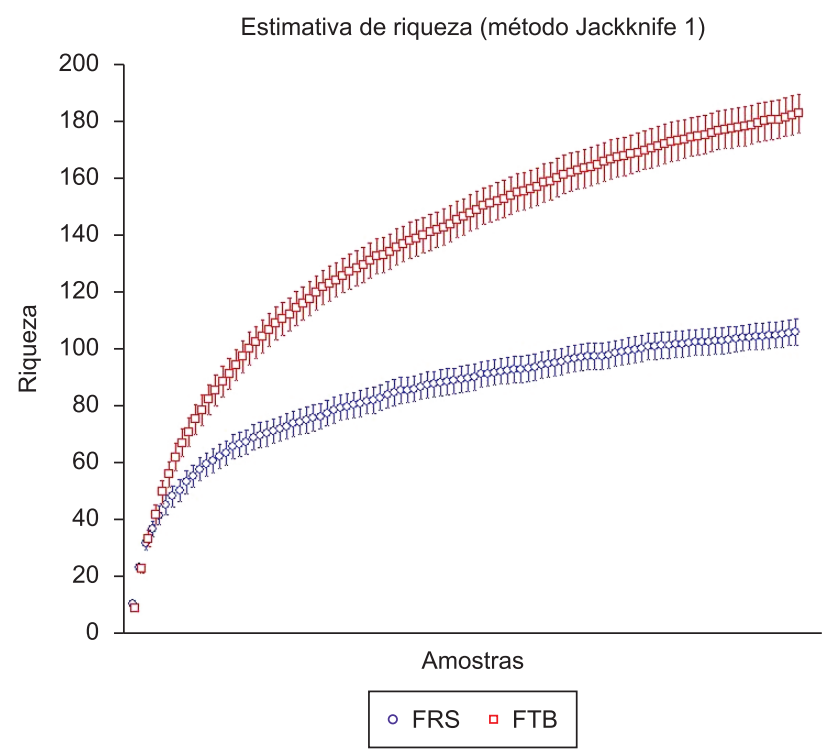

Figura 4. Estimativa de riqueza pelo método Jackknife de primeira ordem para as florestas de Restinga (FRS) e das Terras Baixas (FTB) do Núcleo Picinguaba, Ubatuba, São Paulo, Brasil. As barras verticais indicam os desvios-padrão.

Figure 4. Richness estimate by first order-Jackknife for the Restinga (FRS) and Lowland (FTB) forests at Núcleo Picinguaba/Serra do Mar State Park, Ubatuba, Sao Paulo, Brazil. The vertical bars indicate the standard deviations.

\section{Discussão}

A análise de agrupamento, as ordenações e os testes estatísticos indicaram, em geral, diferenciação edáfica entre a Floresta de Restinga e as Terras Baixas. Na UPGMA, os grupos formados com elevada similaridade continham amostras de apenas um dos sítios, com apenas uma exceção (BSOL5). A PCO e a CA indicaram o mesmo padrão, com as amostras se separando consistentemente no primeiro eixo. $\mathrm{O}$ alto coeficiente de correlação cofenética (na UPGMA) e a boa percentagem de explicação da variância dos dados no primeiro eixo (na PCO e CA) reforçam a confiabilidade desses resultados.

Como esperado, o solo da Floresta de Restinga mostrou-se arenoso, com baixos teores relativos de argila e de carbono e baixos valores de CTC. Os solos da Restinga apresentaram alta saturação por alumínio, indicando que a maior parte dos cátions trocáveis seria constituída por alumínio tóxico. A CTC foi maior nas Terras Baixas provavelmente em decorrência da textura areno-argilosa, e não arenosa como o da Restinga, e da maior associação de suas amostras com a matéria orgânica. $\mathrm{O}$ teor de argila das Terras Baixas foi bastante superior ao encontrado na Restinga. Esses resultados indicam que o solo das Terras Baixas apresenta maior fertilidade que o da Restinga, concordando com Araújo \& Lacerda (1987). Nas restingas, em que a lixiviação tem papel central na perda de minerais, a principal fonte de nutrientes seria a deposição marinha (Leão \& Dominguez 2000), ao passo que nas Terras Baixas os processos de coluvionamento e de fluxo lateral de encosta (Corrêa et al. 2008) têm papel importante na adição de nutrientes. A CTC do solo pode influenciar a estrutura, o regime hídrico e gasoso, a reação do solo e seu processo pedogenético (Vieira 1988) e, por isso, é uma variável relevante no entendimento dos processos ecológicos, como a seleção de espécies em um determinado hábitat. A saturação por alumínio, variável notavelmente associada à Floresta de Restinga, também é um componente importante na seletividade ambiental, uma vez que em elevado teor limita o crescimento e/ou o desenvolvimento dos vegetais (Olmos \& Camargo 1976), principalmente pela inibição do crescimento das raízes (Tecchio et al. 2005).

Além da menor fertilidade e maior toxidez de seus solos, na Restinga estudada também ocorre afloramento periódico do lençol freático (Pedroni 2001, Oliveira \& Joly 2010). Como consequência, a Restinga ofereceria condições mais restritivas ao estabelecimento 
Tabela 3. Listagem florística com número de indivíduos amostrados nas florestas de Restinga (FR) e das Terras Baixas (FT) do Parque Estadual da Serra do Mar, Ubatuba, São Paulo, Brasil.

Table 3. Floristic list with the number of individuals sampled in Restinga (RF) and Lowland (FT) forests at Núcleo Picinguaba/Serra do Mar State Park, Ubatuba, Sao Paulo, Brazil.

\begin{tabular}{|c|c|c|}
\hline Família/espécie - family/species & FR & FT \\
\hline \multicolumn{3}{|l|}{ Anacardiaceae/ } \\
\hline Tapirira guianensis Aubl. & 10 & 0 \\
\hline \multicolumn{3}{|l|}{ Annonaceae/ } \\
\hline Guatteria gomeziana A. St.-Hil. & 71 & 1 \\
\hline Rollinia sericea (R.E. Fr.) R.E. Fr. & 0 & 3 \\
\hline \multicolumn{3}{|l|}{ Apocynaceae/ } \\
\hline Malouetia arborea (Vell.) Miers & 0 & 1 \\
\hline Tabernaemontana laeta Mart. & 1 & 0 \\
\hline \multicolumn{3}{|l|}{ Aquifoliaceae/ } \\
\hline Ilex cf. theezans Mart. & 5 & 0 \\
\hline Ilex dumosa Reissek & 3 & 0 \\
\hline Ilex integerrima Reissek & 10 & 0 \\
\hline \multicolumn{3}{|l|}{ Araliaceae/ } \\
\hline Dendropanax cuneatus (DC.) Decne. \& Planch. & 0 & 1 \\
\hline Oreopanax capitatus (Jacq.) Decne. \& Planch. & 1 & 0 \\
\hline Schefflera angustissima (Marchal) Frodin & 36 & 0 \\
\hline Schefflera calva (Cham.) Frodin \& Fiaschi & 0 & 1 \\
\hline \multicolumn{3}{|l|}{ Arecaceae/ } \\
\hline Astrocaryum aculeatissimum (Schott) Burret & 4 & 6 \\
\hline Bactris setosa Mart. & 1 & 0 \\
\hline Euterpe edulis Mart. & 172 & 115 \\
\hline Syagrus pseudococos (Raddi) Glassman & 0 & 13 \\
\hline \multicolumn{3}{|l|}{ Bignoniaceae/ } \\
\hline Jacaranda puberula Cham. & 88 & 0 \\
\hline \multicolumn{3}{|l|}{ Boraginaceae/ } \\
\hline Cordia sylvestris Fresenius & 0 & 4 \\
\hline Cordia taguahyensis Vell. & 0 & 18 \\
\hline \multicolumn{3}{|l|}{ Cardiopteridaceae/ } \\
\hline Citronella paniculata (Mart.) R.A. Howard & 0 & 13 \\
\hline \multicolumn{3}{|l|}{ Caricaceae/ } \\
\hline Jacaratia heptaphylla (Vell.) A. DC. & 0 & 3 \\
\hline \multicolumn{3}{|l|}{ Celastraceae/ } \\
\hline Cheiloclinium cognatum (Miers) A.C. Sm. & 0 & 2 \\
\hline Maytenus aquifolium Mart. & 0 & 2 \\
\hline Maytenus ardisiifolia Reissek & 0 & 4 \\
\hline Maytenus littoralis Carvalho-Okano & 55 & 0 \\
\hline Maytenus robusta Reissek & 0 & 1 \\
\hline Salacia grandifolia (Mart.) G. Don & 0 & 5 \\
\hline \multicolumn{3}{|l|}{ Chrysobalanaceae/ } \\
\hline Couepia venosa Prance & 2 & 1 \\
\hline Hirtella hebeclada Moric. ex DC. & 2 & 2 \\
\hline \multicolumn{3}{|l|}{ Clusiaceae/ } \\
\hline Calophyllum brasiliense Cambess. & 9 & 0 \\
\hline Clusia criuva Cambess. & 1 & 0 \\
\hline Garcinia gardneriana (Planch. \& Triana) Zappi & 33 & 23 \\
\hline Kielmeyera petiolaris Mart. \& Zucc. & 28 & 0 \\
\hline \multicolumn{3}{|l|}{ Combretaceae/ } \\
\hline Terminalia januarensis DC. & 0 & 7 \\
\hline
\end{tabular}

\begin{tabular}{|c|c|c|}
\hline Família/espécie - family/species & FR & FT \\
\hline \multicolumn{3}{|l|}{ Cyatheaceae/ } \\
\hline Alsophila sternbergii (Sternb.) D.S. Conant & 0 & 12 \\
\hline Cyathea phalerata Mart. & 0 & 2 \\
\hline \multicolumn{3}{|l|}{ Elaeocarpaceae/ } \\
\hline Sloanea guianensis (Aubl.) Benth. & 8 & 23 \\
\hline Sloanea monosperma Vell. & 1 & 1 \\
\hline \multicolumn{3}{|l|}{ Euphorbiaceae/ } \\
\hline Alchornea glandulosa Poepp. & 0 & 2 \\
\hline Alchornea triplinervia (Spreng.) Müll. Arg. & 76 & 1 \\
\hline Mabea piriri Aubl. & 0 & 5 \\
\hline Margaritaria nobilis L. f. & 3 & 0 \\
\hline Pausandra morisiana (Casar.) Radlk. & 0 & 11 \\
\hline Pera glabrata (Schott) Poepp. ex Baill. & 247 & 1 \\
\hline Sapium glandulosum (L.) Morong & 0 & 2 \\
\hline Tetrorchidium rubrivenium Poepp. & 0 & 2 \\
\hline \multicolumn{3}{|l|}{ Fabaceae/ } \\
\hline $\begin{array}{l}\text { Abarema brachystachya (DC.) Barneby \& J.W. } \\
\text { Grimes }\end{array}$ & 3 & 0 \\
\hline Andira fraxinifolia Benth. & 29 & 0 \\
\hline Balizia pedicellaris (DC.) Barneby \& J.W. Grimes & 1 & 0 \\
\hline Dahlstedtia pinnata (Benth.) Malme & 0 & 1 \\
\hline Dalbergia frutescens (Vell.) Britton & 0 & 1 \\
\hline Inga edulis Mart. & 2 & 5 \\
\hline Inga subnuda Salzm. ex Benth. & 22 & 0 \\
\hline $\begin{array}{l}\text { Lonchocarpus cultratus (Vell.) A.M.G. Azevedo } \\
\text { \& H.C. Lima }\end{array}$ & 0 & 2 \\
\hline Myrocarpus frondosus Allemão & 0 & 1 \\
\hline Ormosia arborea (Vell.) Harms & 4 & 0 \\
\hline Pterocarpus rohrii Vahl & 0 & 1 \\
\hline Swartzia oblata R.S. Cowan & 0 & 1 \\
\hline Swartzia simplex (Sw.) Spreng. & 4 & 4 \\
\hline Tachigali denudata (Vogel) Oliveira-Filho & 1 & 1 \\
\hline Zollernia ilicifolia (Brongn.) Vogel & 0 & 7 \\
\hline \multicolumn{3}{|l|}{ Lacistemataceae/ } \\
\hline Lacistema pubescens Mart. & 8 & 0 \\
\hline \multicolumn{3}{|l|}{ Lamiaceae } \\
\hline Vitex cymosa Bertero ex Spreng. & 1 & 0 \\
\hline \multicolumn{3}{|l|}{ Lauraceae/ } \\
\hline Cryptocarya aschersoniana $\mathrm{Mez}$ & 0 & 1 \\
\hline Cryptocarya moschata Nees \& C.Mart. & 0 & 2 \\
\hline Cryptocarya saligna Mez. & 0 & 7 \\
\hline Cryptocarya mandiocana Meisn. & 0 & 3 \\
\hline Endlicheria paniculata (Spreng.) J.F. Macbr. & 4 & 14 \\
\hline Nectandra oppositifolia Nees \& Mart. & 28 & 0 \\
\hline Nectandra psammophila Nees \& C. Mart. & 1 & 0 \\
\hline Ocotea dispersa (Nees) Mez & 0 & 8 \\
\hline Ocotea divaricata (Nees) $\mathrm{Mez}$ & 0 & 1 \\
\hline Ocotea rariflora (Meisn.) Baitello & 1 & 0 \\
\hline
\end{tabular}


Tabela 3. Continuação.

\begin{tabular}{|c|c|c|}
\hline Família/espécie - family/species & FR & FT \\
\hline \multicolumn{3}{|l|}{ Lecythidaceae/ } \\
\hline Cariniana estrellensis (Raddi) Kuntze & 0 & 1 \\
\hline \multicolumn{3}{|l|}{ Magnoliaceae/ } \\
\hline Magnolia ovata (A. St.-Hil.) Spreng. & 0 & 1 \\
\hline \multicolumn{3}{|l|}{ Malpighiaceae/ } \\
\hline Byrsonima ligustrifolia A. St.-Hil. & 5 & 0 \\
\hline \multicolumn{3}{|l|}{ Malvaceae/ } \\
\hline Eriotheca pentaphylla (Vell.) A. Robyns & 0 & 13 \\
\hline Quararibea turbinata (Sw.) Poir. & 0 & 5 \\
\hline \multicolumn{3}{|l|}{ Melastomataceae/ } \\
\hline Miconia cinnamomifolia (DC.) Naudin & 1 & 0 \\
\hline Miconia dodecandra Cogn. & 5 & 0 \\
\hline Miconia prasina (Sw.) DC. & 10 & 0 \\
\hline Miconia rigidiuscula Cogn. & 13 & 0 \\
\hline Tibouchina pulchra & 1 & 0 \\
\hline \multicolumn{3}{|l|}{ Meliaceae/ } \\
\hline Cabralea cangerana Saldanha & 0 & 2 \\
\hline Guarea macrophylla Vahl & 64 & 1 \\
\hline Trichilia lepidota Mart. & 0 & 1 \\
\hline Trichilia silvatica C. DC. & 0 & 5 \\
\hline \multicolumn{3}{|l|}{ Monimiaceae/ } \\
\hline Mollinedia cyathantha Perkins & 0 & 1 \\
\hline Mollinedia engleriana Perkins & 0 & 2 \\
\hline Mollinedia lamprophylla Perkins & 0 & 1 \\
\hline Mollinedia oligantha Perkins & 0 & 1 \\
\hline Mollinedia schottiana (Spreng.) Perkins & 0 & 76 \\
\hline \multicolumn{3}{|l|}{ Moraceae/ } \\
\hline Brosimum guianense (Aubl.) Huber & 0 & 1 \\
\hline Coussapoa microcarpa (Schott) Rizzini & 5 & 2 \\
\hline Ficus gomelleira Kunth \& C.D. Bouché & 0 & 2 \\
\hline Ficus insipida Willd. & 1 & 2 \\
\hline Ficus pulchella Schott ex Spreng. & 0 & 1 \\
\hline $\begin{array}{l}\text { Sorocea bonplandii (Baill.) W.C. Burger, Lanj. \& } \\
\text { Wess. Boer }\end{array}$ & 0 & 8 \\
\hline Sorocea hilarii Gaudich. & 0 & 2 \\
\hline Sorocea jureiana Romaniuc & 2 & 0 \\
\hline \multicolumn{3}{|l|}{ Myristicaceae/ } \\
\hline Virola bicuhyba (Schott ex Spreng.) Warb. & 1 & 22 \\
\hline \multicolumn{3}{|l|}{ Myrsinaceae/ } \\
\hline Ardisia martiana Miq. & 0 & 5 \\
\hline Rapanea ferruginea (Ruiz \& Pav.) Mez & 6 & 0 \\
\hline Rapanea venosa (A. DC.) Mez & 33 & 0 \\
\hline \multicolumn{3}{|l|}{ Myrtaceae/ } \\
\hline Calyptranthes concinna DC. & 13 & 0 \\
\hline Calyptranthes lucida Mart. ex DC. & 2 & 7 \\
\hline Calyptranthes rufa O. Berg & 0 & 1 \\
\hline Calyptranthes strigipes O. Berg & 0 & 10 \\
\hline Campomanesia guaviroba (DC.) Kiaersk. & 1 & 10 \\
\hline $\begin{array}{l}\text { Campomanesia } \text { cf. schlechtendahliana (O. Berg) } \\
\text { Nied. }\end{array}$ & 0 & 2 \\
\hline Eugenia aff. monosperma Vell. & 1 & 0 \\
\hline
\end{tabular}

\begin{tabular}{|c|c|c|}
\hline Família/espécie - family/species & FR & FT \\
\hline Eugenia brasiliensis Lam. & 11 & 0 \\
\hline Eugenia cerasiflora Miq. & 0 & 1 \\
\hline Eugenia cf. pleurantha O. Berg & 4 & 0 \\
\hline Eugenia cf. bocainensis Mattos & 0 & 1 \\
\hline Eugenia cf. cereja & 0 & 19 \\
\hline Eugenia cf. mosenii (Kasusel) Sobral & 0 & 1 \\
\hline Eugenia fusca O. Berg & 6 & 11 \\
\hline Eugenia linguaeformis O. Berg & 0 & 11 \\
\hline Eugenia magnibracteolata Mattos \& D. Legrand & 0 & 3 \\
\hline Eugenia melanogyna (D. Legrand) Sobral & 0 & 13 \\
\hline Eugenia multicostata D. Legrand & 0 & 4 \\
\hline Eugenia neoaustralis Sobral & 0 & 6 \\
\hline Eugenia oblongata O. Berg & 0 & 20 \\
\hline Eugenia plicata Nied. & 0 & 2 \\
\hline Eugenia prasina $\mathrm{O}$. Berg & 0 & 3 \\
\hline Eugenia speciosa Cambess. & 7 & 0 \\
\hline Eugenia subavenia $\mathrm{O}$. Berg & 0 & 4 \\
\hline Eugenia umbelliflora O. Berg & 12 & 0 \\
\hline Eugenia verticillata (Velloso) Angely & 35 & 0 \\
\hline Gomidesia blanchetiana O. Berg & 0 & 1 \\
\hline Marlierea cf. racemosa (Vell.) Kiaersk. & 0 & 2 \\
\hline Marlierea glazioviana Kiareskou & 0 & 7 \\
\hline Marlierea obscura O. Berg & 3 & 17 \\
\hline Marlierea silvatica (Gardner) Kiaersk. & 0 & 5 \\
\hline Marlierea tomentosa Cambess. & 32 & 9 \\
\hline Myrcia brasiliensis Kiaersk. & 86 & 0 \\
\hline Myrcia floribunda Miq. & 0 & 1 \\
\hline Myrcia insularis Kiaersk. & 1 & 0 \\
\hline Myrcia multiflora (Lam.) DC. & 67 & 0 \\
\hline Myrcia pubipetala Miq. & 1 & 3 \\
\hline Myrcia spectabilis DC. & 1 & 18 \\
\hline Myrcia splendens (Sw.) DC. & 7 & 0 \\
\hline Myrcia racemosa (O. Berg) Kiaersk. & 147 & 0 \\
\hline Myrciaria floribunda (H. West ex Willd.) O. Berg & 0 & 6 \\
\hline Psidium cattleianum Sabine & 2 & 0 \\
\hline Syzygium jambos (L.) Alston & 5 & 0 \\
\hline \multicolumn{3}{|l|}{ Nyctaginaceae/ } \\
\hline Guapira opposita (Vell.) Reitz & 28 & 42 \\
\hline \multicolumn{3}{|l|}{ Ochnaceae/ } \\
\hline Ouratea parviflora DC. (Baill.) & 0 & 1 \\
\hline \multicolumn{3}{|l|}{ Olacaceae/ } \\
\hline Heisteria silvianii Schwacke & 0 & 2 \\
\hline Tetrastylidium grandifolium (Baill.) Sleumer & 0 & 3 \\
\hline \multicolumn{3}{|l|}{ Piperaceae/ } \\
\hline Piper cernuum Vell. & 0 & 1 \\
\hline \multicolumn{3}{|l|}{ Phyllanthaceae/ } \\
\hline Hyeronima alchorneoides Allemão & 4 & 5 \\
\hline \multicolumn{3}{|l|}{ Polygonaceae/ } \\
\hline Coccoloba glaziovii Lindau & 5 & 0 \\
\hline Ruprechtia laxiflora Meisn. & 0 & 2 \\
\hline
\end{tabular}


Tabela 3. Continuação.

\begin{tabular}{lrr}
\hline \multicolumn{1}{c}{ Família/espécie - family/species } & FR & FT \\
\hline Proteaceae/ & 22 & 0 \\
$\quad$ Euplassa cantareirae Sleumer & 3 & 1 \\
$\quad$ Roupala brasiliensis Klotzsch & & \\
Quiinaceae/ & 0 & 2 \\
$\quad$ Quiina glazovii Engl. & & \\
Rosaceae/ & 1 & 1 \\
Prunus myrtifolia (L.) Urb. & & \\
Rubiaceae/ & 0 & 7 \\
Alseis floribunda Schott & 12 & 0 \\
Amaioua intermedia Mart. & 0 & 5 \\
Bathysa australis (A. St.-Hil.) Benth. \& Hook. f. & 0 & 30 \\
Bathysa mendoncaei K. Schum. & 0 & 2 \\
Bathysa stipulata (Vell.) J. Presl & 0 & 40 \\
Coussarea accedens Müll. Arg. & 0 & 63 \\
Coussarea meridionalis (Vell.) Müll. Arg. & 14 & 1 \\
Faramea pachyantha Müll. Arg. & 0 & 7 \\
Faramea picinguabae M.Gomes & 5 & 0 \\
Genipa infundibuliformis Zappi \& Semir & 0 & 1 \\
Guettarda viburnoides Cham. \& Schltdl. & &
\end{tabular}

\begin{tabular}{lrr}
\hline \multicolumn{1}{c}{ Família/espécie - family/species } & FR & FT \\
\hline Ixora bracteolaris Müll. Arg. & 0 & 2 \\
Rudgea vellerea Müll. Arg. & 0 & 11 \\
Rustia formosa (Cham. \& Schltdl. ex DC.) Klotzsch & 0 & 59 \\
Simira sampaioana (Standl.) Steyerm. & 0 & 2 \\
Sapindaceae/ & & \\
Allophylus petiolulatus Radlk. & 0 & 2 \\
Cupania oblongifolia Mart. & 3 & 5 \\
Matayba elaeagnoides Radlk. & 3 & 0 \\
Sapotaceae/ & & \\
Chrysophyllum flexuosum Mart. & 0 & 51 \\
Chrysophyllum viride Mart. \& Eichler & 0 & 1 \\
Ecclinusa ramiflora Mart. & 0 & 1 \\
Micropholis crassipedicellata (Mart. \& Eichler ex & 0 & 1 \\
Miq.) Pierre & & \\
Pouteria caimito (Ruiz \& Pav.) Radlk. & 0 & 4 \\
Pouteria cf. psammophila (Mart.) Radlk. & 0 & 1 \\
Pouteria cf. venosa (Mart.) Baehni & 0 & 17 \\
Urticaceae/ & & \\
Cecropia glaziovi Snethl. & 3 & 2 \\
\hline
\end{tabular}

Tabela 4. Trabalhos utilizados na comparação florística com as florestas de Restinga e das Terras Baixas do Parque Estadual da Serra do Mar, Ubatuba, São Paulo, Brasil. Todos utilizaram o método de parcelas. Quando presente, a amplitude de variação de H' refere-se a trabalhos que efetuaram vários levantamentos, mas que, em conjunto, constituíram uma única listagem utilizada para os fins desta comparação.

Table 4. Papers used in the floristic comparison with the Restinga and Lowland forests from Núcleo Picinguaba/Serra do Mar State Park, Ubatuba, Sao Paulo, Brazil. All these authors used the plot method. When present, the variations of $\mathrm{H}$ 'refers to authors that carried out various surveys, but which, considered together, constituted a single list used for the purposes of this comparison

\begin{tabular}{|c|c|c|c|c|c|c|c|}
\hline Fisionomia/Estado & $\begin{array}{c}\text { Código no } \\
\text { dendrograma }\end{array}$ & $\begin{array}{l}\text { Altitude } \\
\text { média }\end{array}$ & $\begin{array}{l}\text { Coordenadas } \\
\text { geográficas } \\
\text { aproximadas }\end{array}$ & $\begin{array}{l}\text { Critério de } \\
\text { inclusão }\end{array}$ & $\begin{array}{c}\text { Área } \\
\text { amostrada }\end{array}$ & $\begin{array}{c}\text { H' }^{\prime} \\
\text { (Shannon) }\end{array}$ & Referência \\
\hline $\begin{array}{l}\text { Floresta de } \\
\text { Restinga/SP }\end{array}$ & $\begin{array}{l}\text { REST- } \\
\text { FRS }\end{array}$ & $\begin{array}{l}\text { Nível } \\
\text { do mar }\end{array}$ & $\begin{array}{l}23^{\circ} 20^{\prime}-23^{\circ} 22^{\prime} \mathrm{S} ; \\
44^{\circ} 46^{\prime}-44^{\circ} 51^{\prime} \mathrm{W}\end{array}$ & $\begin{array}{l}\text { DAP > } \\
4,8 \mathrm{~cm}\end{array}$ & $1 \mathrm{ha}$ & 3,38 & $\begin{array}{c}\text { Este } \\
\text { estudo }\end{array}$ \\
\hline $\begin{array}{l}\text { Floresta de } \\
\text { Restinga/ES }\end{array}$ & $\begin{array}{c}\text { REST- } \\
\text { Setiba/ES }\end{array}$ & $\begin{array}{l}\text { Nível } \\
\text { do mar }\end{array}$ & $\begin{array}{l}20^{\circ} 33^{\prime}-20^{\circ} 38^{\prime} \mathrm{S} ; \\
40^{\circ} 23^{\prime}-40^{\circ} 26^{\prime} \mathrm{W}\end{array}$ & $\begin{array}{l}\text { DAP > } \\
4,8 \mathrm{~cm}\end{array}$ & 1 ha & 3,73 & $\begin{array}{l}\text { Assis et al. } \\
\text { (2004) }\end{array}$ \\
\hline $\begin{array}{l}\text { Floresta de } \\
\text { Restinga/RS }\end{array}$ & $\begin{array}{c}\text { REST- } \\
\text { Viamão/RS }\end{array}$ & $\begin{array}{l}\text { Nível } \\
\text { do mar }\end{array}$ & $\begin{array}{c}30^{\circ} 23^{\prime} \mathrm{S} ; \\
50^{\circ} 59^{\prime}-51^{\circ} 01^{\prime} \mathrm{W}\end{array}$ & $\begin{array}{l}\text { DAP > } \\
5 \mathrm{~cm}\end{array}$ & 1,02 ha & 1,08 a 2,38 & $\begin{array}{l}\text { Scherer et al. } \\
\text { (2005) }\end{array}$ \\
\hline $\begin{array}{l}\text { Floresta de } \\
\text { Restinga/SP }\end{array}$ & $\begin{array}{c}\text { REST- } \\
\text { Pariq_Açu/SP }\end{array}$ & $\begin{array}{l}\text { Nível } \\
\text { do mar }\end{array}$ & $24^{\circ} 40^{\prime} \mathrm{S} ; 47^{\circ} 48^{\prime} \mathrm{W}$ & $\begin{array}{l}\text { DAP > } \\
4,8 \mathrm{~cm}\end{array}$ & 0,54 ha & 4,06 & $\begin{array}{c}\text { Sztutman \& } \\
\text { Rodrigues (2002) }\end{array}$ \\
\hline $\begin{array}{l}\text { Floresta Ombrófila Densa } \\
\text { Atlântica de Encosta/SP }\end{array}$ & $\begin{array}{l}\text { ENCST- } \\
\text { FTB }\end{array}$ & $50 \mathrm{~m}$ & $\begin{array}{l}23^{\circ} 20^{\prime}-23^{\circ} 22^{\prime} \mathrm{S} ; \\
44^{\circ} 46^{\prime}-44^{\circ} 51^{\prime} \mathrm{W}\end{array}$ & $\begin{array}{l}\mathrm{DAP}> \\
4,8 \mathrm{~cm}\end{array}$ & 1 ha & 4,00 & $\begin{array}{c}\text { Este } \\
\text { estudo }\end{array}$ \\
\hline $\begin{array}{l}\text { Floresta Ombrófila Densa } \\
\text { Atlântica de Encosta/ SC }\end{array}$ & $\begin{array}{c}\text { ENCST- } \\
\text { Alcântara/SC }\end{array}$ & $300 \mathrm{~m}$ & $27-28^{\circ} \mathrm{S} ; 48-49^{\prime} \mathrm{W}$ & $\begin{array}{l}\mathrm{DAP}> \\
5 \mathrm{~cm}\end{array}$ & 1,5 ha & 3,28 a 3,95 & $\begin{array}{l}\text { Mantovani et al. } \\
\text { (2005) }\end{array}$ \\
\hline $\begin{array}{l}\text { Floresta Ombrófila Densa } \\
\text { Atlântica de Encosta/SP }\end{array}$ & $\begin{array}{c}\text { ENCST- } \\
\text { Intervales/SP }\end{array}$ & $\begin{array}{c}70 \mathrm{a} \\
250 \mathrm{~m}\end{array}$ & $24^{\circ} 14^{\prime} \mathrm{S} ; 48^{\circ} 04^{\prime} \mathrm{W}$ & $\begin{array}{l}\mathrm{DAP}> \\
5 \mathrm{~cm}\end{array}$ & 0,99 ha & 3,85 & $\begin{array}{l}\text { Guilherme et al. } \\
\qquad(2004)\end{array}$ \\
\hline $\begin{array}{l}\text { Floresta Ombrófila Densa } \\
\text { Atlântica de Encosta/RJ }\end{array}$ & $\begin{array}{l}\text { ENCST- } \\
\text { Fragm.I/RJ }\end{array}$ & $<200 \mathrm{~m}$ & $\begin{array}{l}22^{\circ} 30^{\prime}-22^{\circ} 35^{\prime} \mathrm{S} ; \\
42^{\circ} 14^{\prime} ; 42^{\circ} 19^{\prime} \mathrm{W}\end{array}$ & $\begin{array}{l}\text { DAP > } \\
5 \mathrm{~cm}\end{array}$ & 0,225 ha & 3,02 & $\begin{array}{c}\text { Pessoa \& } \\
\text { Oliveira }(2006)\end{array}$ \\
\hline $\begin{array}{l}\text { Floresta Ombrófila Densa } \\
\text { Atlântica de Encosta/RJ }\end{array}$ & $\begin{array}{c}\text { ENCST- } \\
\text { Fragm.II/RJ }\end{array}$ & $<200 \mathrm{~m}$ & $\begin{array}{l}22^{\circ} 30^{\prime}-22^{\circ} 35^{\prime} \mathrm{S} ; \\
42^{\circ} 14^{\prime} ; 42^{\circ} 19^{\prime} \mathrm{W}\end{array}$ & $\begin{array}{l}\text { DAP > } \\
5 \mathrm{~cm}\end{array}$ & 0,575 ha & 3,90 & $\begin{array}{c}\text { Pessoa \& } \\
\text { Oliveira (2006) }\end{array}$ \\
\hline $\begin{array}{l}\text { Floresta Ombrófila Densa } \\
\text { Atlântica de Encosta/RJ }\end{array}$ & $\begin{array}{c}\text { ENCST- } \\
\text { Fragm.III/RJ }\end{array}$ & $<200 \mathrm{~m}$ & $\begin{array}{l}22^{\circ} 30^{\prime}-22^{\circ} 35^{\prime} \mathrm{S} ; \\
42^{\circ} 14^{\prime} ; 42^{\circ} 19^{\prime} \mathrm{W}\end{array}$ & $\begin{array}{l}\text { DAP > } \\
5 \mathrm{~cm}\end{array}$ & 0,65 ha & 3,65 & $\begin{array}{c}\text { Pessoa \& } \\
\text { Oliveira }(2006)\end{array}$ \\
\hline
\end{tabular}




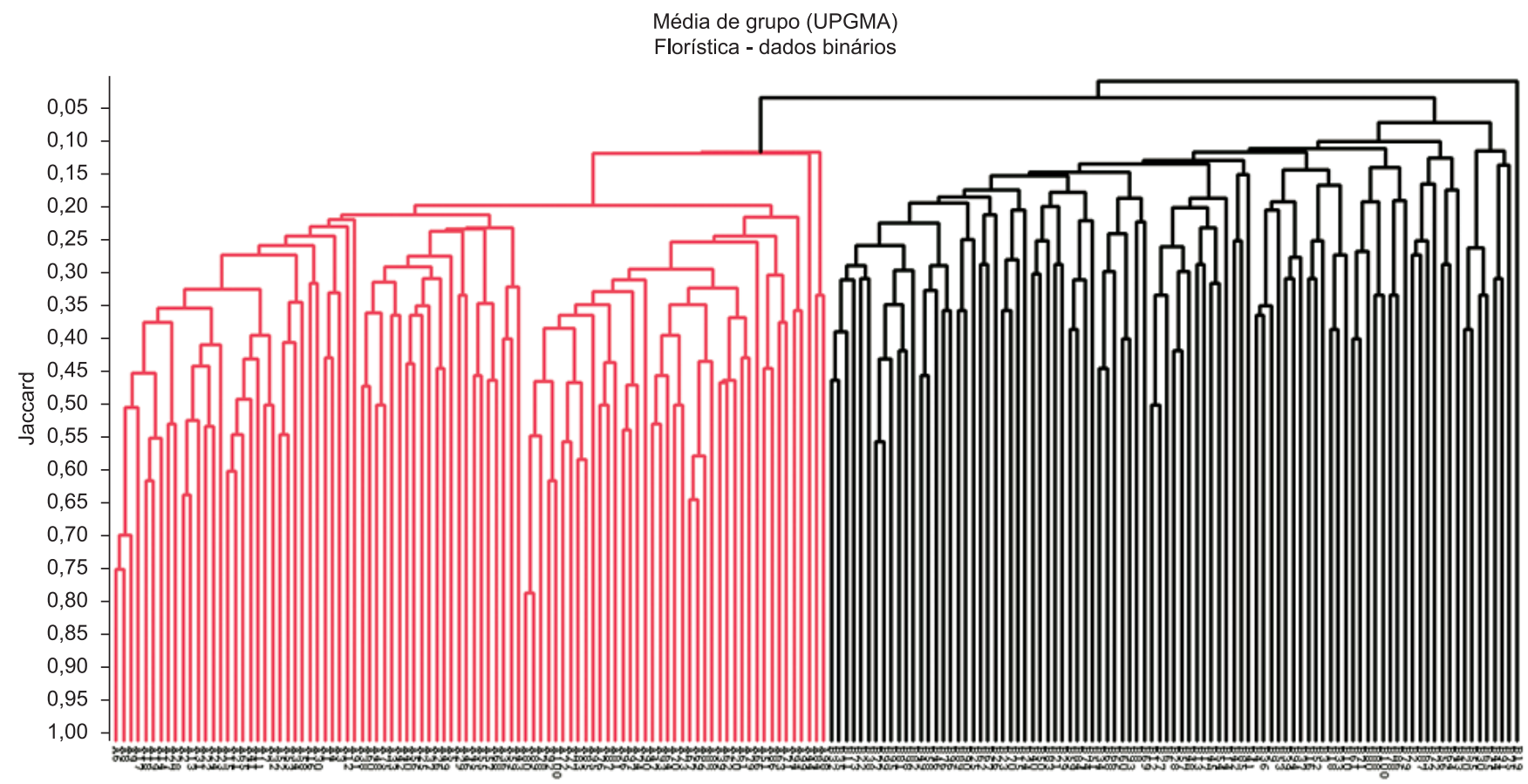

Figura 5. Análise de Agrupamento pelo método UPGMA para a matriz de ocorrência das espécies amostradas nas florestas de Restinga e das Terras Baixas do Núcleo Picinguaba, Ubatuba, São Paulo, Brasil.

Figure 5. Cluster analysis by UPGMA method for matrix of species occurrence in the Restinga and Lowland forests at Núcleo Picinguaba/Serra do Mar State Park, Ubatuba, Sao Paulo, Brazil.

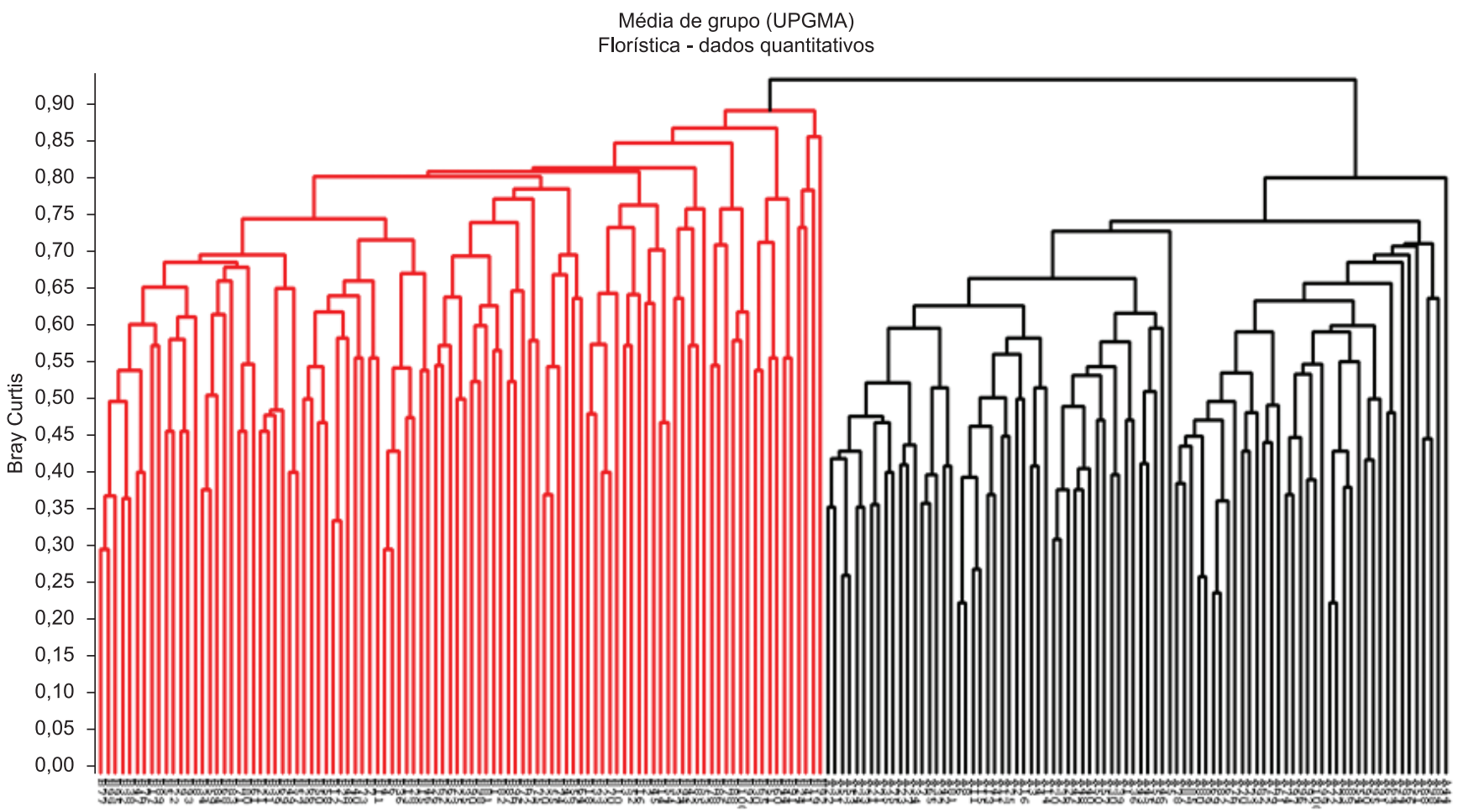

Figura 6. Análise de Agrupamento pelo método UPGMA para a matriz de abundância das espécies amostradas nas florestas de Restinga e das Terras Baixas do Núcleo Picinguaba, Ubatuba, São Paulo, Brasil.

Figure 6. Cluster analysis by UPGMA method for matrix of species abundance in the Restinga and Lowland forests at Núcleo Picinguaba/Serra do Mar State Park, Ubatuba, Sao Paulo, Brazil. 


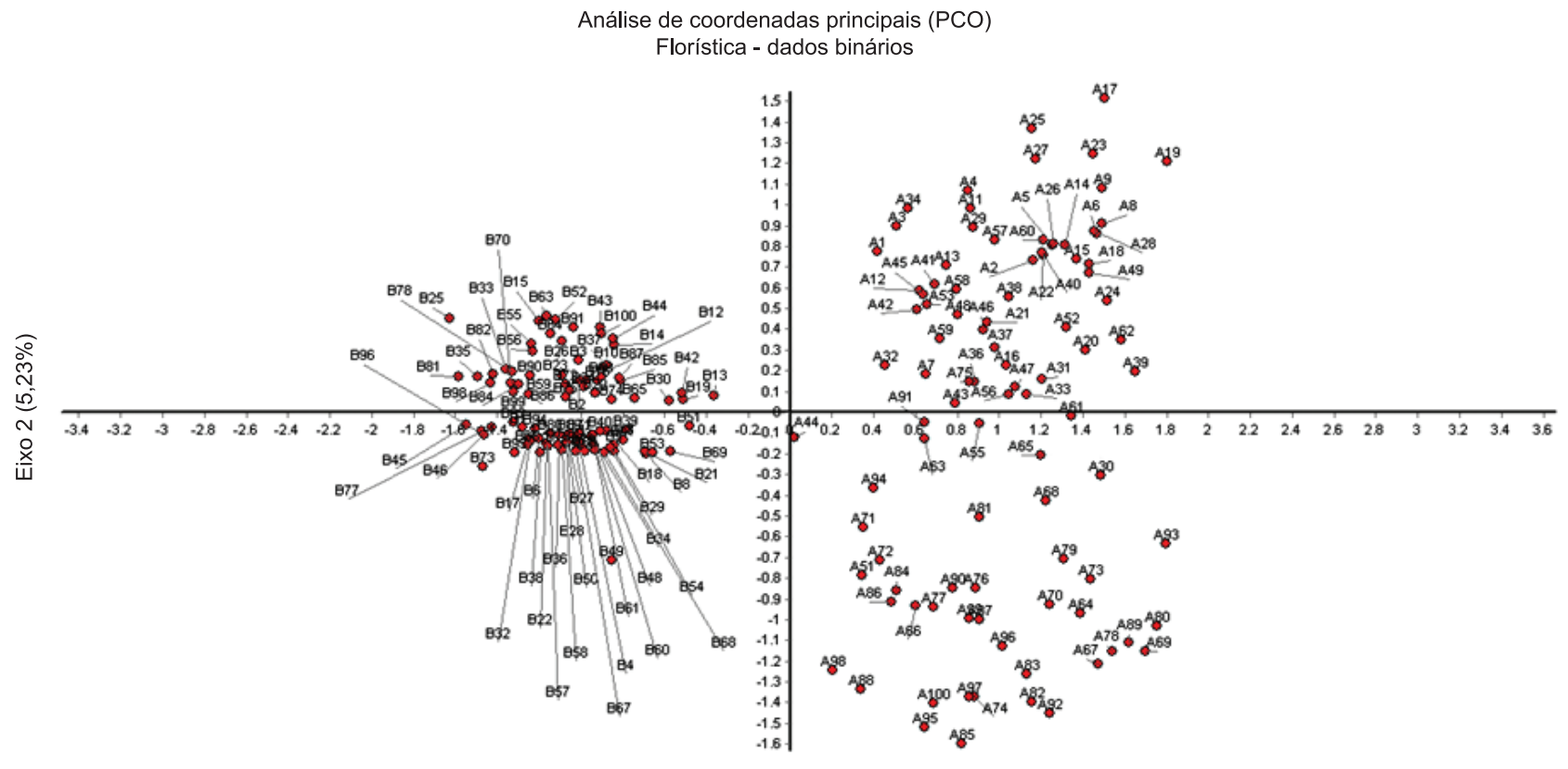

Eixo $1(16,14 \%)$

Figura 7. Ordenação por PCO para a matriz de ocorrência das espécies amostradas nas florestas de Restinga (indicadas pela letra A seguida do número da parcela) e das Terras Baixas (letra B mais o número da parcela) do Núcleo Picinguaba, Ubatuba, São Paulo, Brasil.

Figure 7. PCO ordination for matrix of species occurrence in the Restinga (indicated by the letter A followed by the number of the plot) and Lowland (letter B plus the number of the plot) forests at Núcleo Picinguaba/Serra do Mar State Park, Ubatuba, Sao Paulo, Brazil.

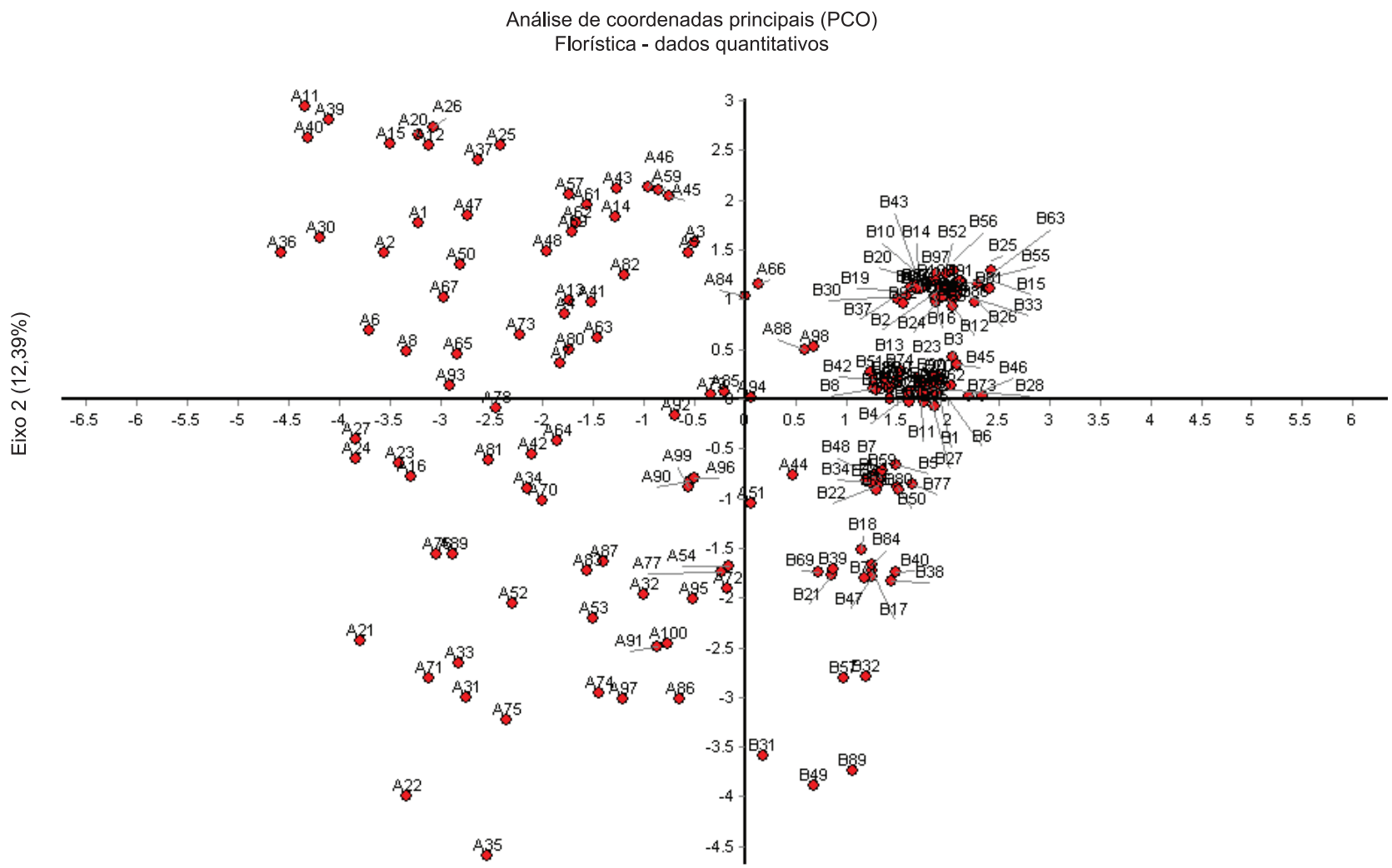

Eixo $1(21,41 \%)$

Figura 8. Ordenação por PCO para a matriz de abundância das espécies amostradas nas florestas de Restinga (indicadas pela letra A seguida do número da parcela) e das Terras Baixas (letra B mais o número da parcela) do Núcleo Picinguaba, Ubatuba, São Paulo, Brasil.

Figure 8. PCO ordination for matrix of species abundance in the Restinga (indicated by the letter A followed by the number of the plot) and Lowland (letter B plus the number of the plot) forests at Núcleo Picinguaba/Serra do Mar State Park, Ubatuba, Sao Paulo, Brazil. 


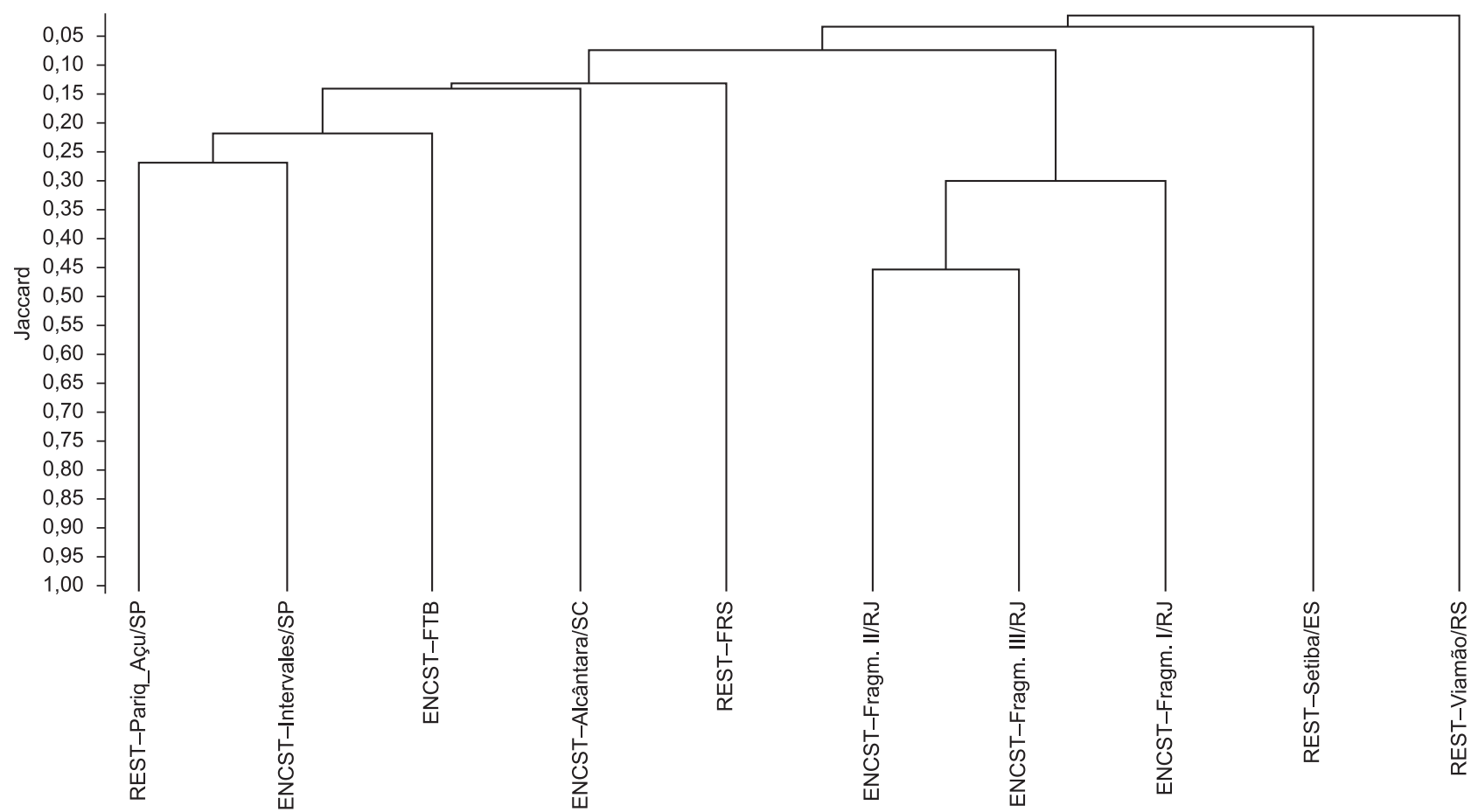

Figura 9. Dendrograma resultante da análise de similaridade florística (UPGMA, dados binários) entre os levantamentos nas florestas de Restinga (REST-FRS) e das Terras Baixas (ENCST-FTB) de Picinguaba/Serra do Mar, Ubatuba, São Paulo, Brasil com outros levantamentos na Mata Atlântica. REST: florestas de Restinga; ENCST: florestas de encosta. Informações sobre os levantamentos podem ser obtidas na tabela 4.

Figure 9. Dendrogram resulted from the floristic similarity analysis (UPGMA, binary data) between surveys in the Restinga (REST-FRS) and Lowland (ENCST-FTB) forests at Núcleo Picinguaba/Serra do Mar State Park, Ubatuba, Sao Paulo, Brazil with other surveys in the Atlantic Forest. REST: Restinga forests; ENCST: hillside forests. Information about the surveys can be seen in Table 4.

de espécies do que as Terras Baixas. A ação de diferentes processos geomorfológicos parece ter resultado em solos com características físico-químicas distintas na Restinga e nas Terras Baixas, o que poderia condicionar diferenças na composição florística e no funcionamento entre a Floresta de Restinga e as Terras Baixas.

Houve baixa similaridade florística entre o componente arbóreo da Floresta de Restinga e das Terras Baixas. Dentre as poucas espécies em comum, destacam-se: Euterpe edulis, a palmeira com maior abundância e constância na Mata Atlântica do estado de São Paulo (Scudeller et al. 2001); Guapira opposita, que tem ampla distribuição em florestas extra-amazônicas e cerrados (Scudeller 2002); Marlierea tomentosa, que ocorre também na Floresta Estacional Semidecídua e em cerrados; e Sloanea guianensis, que ocorre principalmente na Floresta Ombrófila Densa. Era de fato esperado que Garcinia gardneriana, considerada uma espécie amplamente distribuída na Mata Atlântica, fosse uma espécie comum à Restinga e Terras Baixas, ocorrendo com grande abundância em ambas as florestas.

A baixa similaridade florística entre as duas áreas estudadas já era esperada, uma vez que a suposição inicial deste trabalho - confirmada pelos resultados de solos - previa um ambiente mais restritivo na Restinga. A dissimilaridade foi reforçada pelos dendrogramas, que mostraram a separação de dois grandes blocos, cada um contendo apenas parcelas de uma das florestas. As ordenações por PCO também mostraram clara separação entre as espécies da Restinga e das Terras Baixas.

A elevada riqueza da família Myrtaceae encontrada na Floresta de Restinga parece ser uma constante nesse tipo de vegetação. Por exemplo, no trabalho de Assis et al. (2004), em Guarapari
(Espírito Santo), 21,74\% das espécies registradas pertencem a essa família. Trabalhos feitos em restingas do Nordeste (por exemplo, Sacramento et al. 2007) também apontam nesse sentido. As famílias mais ricas (Myrtaceae e Rubiaceae) das Terras Baixas aparecem com grande riqueza em outros levantamentos na Floresta Ombrófila Densa do estado de São Paulo, independentemente da cota altitudinal, como na Ilha do Cardoso (Melo \& Mantovani 1994) e no próprio município de Ubatuba (Silva \& Leitão-Filho 1982). Myrtaceae também se destacou em riqueza de espécies em outra área de parcelas permanentes no estado de São Paulo, no Núcleo Sete Barras do Parque Estadual Carlos Botelho (Eisenlohr et al. 2011).

Com exceção de Rustia formosa, que apareceu como indicadora apenas na análise qualitativa, houve convergência dos resultados da análise das demais espécies indicadoras na TWINSPAN a partir das matrizes binária e quantitativa. Portanto, essas espécies indicadoras coincidentes nas duas análises não somente ocorreram com frequência diferenciada, mas também apresentaram abundância diferenciada em uma ou outra floresta. Essa convergência nos faz supor que, independentemente do potencial de colonização de cada espécie, a simples ocorrência de espécies particulares parece ser determinada, em boa medida, pelos fatores abióticos que caracterizam as áreas ocupadas por estas duas florestas, especialmente as características físico-químicas dos solos e a saturação hídrica sazonal da Restinga. Embora César \& Monteiro (1995) não tenham efetuado análise de espécies indicadoras, em sua amostragem as espécies Pera glabrata e Eugenia racemosa foram amostradas com grande abundância na mesma Floresta de Restinga de Ubatuba. Brown \& Lomolino (2006) ressaltaram que uma espécie muito abundante tende a habitar locais em que as variáveis ambientais condicionantes do nicho 
Comparação florestas de restinga e de terras baixas

Tabela 5. Produção de serapilheira para cada quinzena de coleta na Floresta da Restinga no Parque Estadual da Serra do Mar, Ubatuba, São Paulo, Brasil. Table 5. Litterfall production, sampled every fortnight, by the Restinga Forest at Núcleo Picinguaba/Serra do Mar State Park, Ubatuba, Sao Paulo, Brazil.

\begin{tabular}{|c|c|c|c|c|c|}
\hline $\begin{array}{c}\text { Data } \\
\text { de coleta }\end{array}$ & $\begin{array}{c}\text { Total } \\
\left(\text { t.ha }^{-1}\right)\end{array}$ & $\begin{array}{c}\text { Média } \pm \text { DP } \\
\left(\text { t.ha }^{-1}\right)\end{array}$ & $\begin{array}{c}\text { Mediana } \\
(\text { t.ha } \\
\text {-1 })\end{array}$ & $\begin{array}{c}\text { Número efetivo } \\
\text { de coletas }\end{array}$ & $\begin{array}{c}\text { Amplitude de } \\
\text { variação }\left(\text { t.ha }^{-1}\right)\end{array}$ \\
\hline $28 / 03 / 2007$ & 0,5004 & $0,0179 \pm 0,0068$ & 0,0170 & 28 & $0,0080-0,0329$ \\
\hline $18 / 04 / 2007$ & 0,3639 & $0,0121 \pm 0,0058$ & 0,0114 & 30 & $0,0043-0,0268$ \\
\hline $30 / 04 / 2007$ & 0,2941 & $0,0105 \pm 0,0050$ & 0,0098 & 28 & $0,0043-0,0208$ \\
\hline $15 / 05 / 2007$ & 0,3192 & $0,0106 \pm 0,0058$ & 0,0084 & 30 & $0,0019-0,0274$ \\
\hline $29 / 05 / 2007$ & 0,1426 & $0,0051 \pm 0,0030$ & 0,0042 & 28 & $0,0010-0,0126$ \\
\hline $14 / 06 / 2007$ & 0,1964 & $0,0068 \pm 0,0053$ & 0,0057 & 29 & $0,0009-0,0254$ \\
\hline $29 / 06 / 2007$ & 0,1231 & $0,0044 \pm 0,0032$ & 0,0032 & 28 & $0,0013-0,0137$ \\
\hline $13 / 07 / 2007$ & 0,0853 & $0,0030 \pm 0,0019$ & 0,0026 & 28 & $0,0006-0,0072$ \\
\hline 28/07/2007 & 0,5412 & $0,0187 \pm 0,0082$ & 0,0168 & 29 & $0,0028-0,0372$ \\
\hline $15 / 08 / 2007$ & 0,1084 & $0,0040 \pm 0,0021$ & 0,0039 & 27 & $0,0014-0,010$ \\
\hline $29 / 08 / 2007$ & 0,0926 & $0,0031 \pm 0,0014$ & 0,0032 & 30 & $0,0005-0,006$ \\
\hline $17 / 09 / 2007$ & 0,1464 & $0,0052 \pm 0,0020$ & 0,0049 & 28 & $0,0019-0,0097$ \\
\hline 01/10/2007 & 0,2256 & $0,0075 \pm 0,0029$ & 0,0072 & 30 & $0,0023-0,0144$ \\
\hline $15 / 10 / 2007$ & 0,1488 & $0,0051 \pm 0,0024$ & 0,0052 & 29 & $0,0012-0,0101$ \\
\hline $26 / 10 / 2007$ & 0,2312 & $0,0080 \pm 0,0041$ & 0,0072 & 29 & $0,0006-0,0172$ \\
\hline $17 / 11 / 2007$ & 0,5987 & $0,0206 \pm 0,0074$ & 0,0207 & 29 & $0,0083-0,0377$ \\
\hline $01 / 12 / 2007$ & 0,2066 & $0,0079 \pm 0,0026$ & 0,0077 & 26 & $0,0032-0,0141$ \\
\hline $15 / 12 / 2007$ & 0,3259 & $0,0112 \pm 0,0046$ & 0,0104 & 29 & $0,0024-0,0211$ \\
\hline $28 / 12 / 2007$ & 0,2526 & $0,0084 \pm 0,0038$ & 0,0078 & 30 & $0,0015-0,0158$ \\
\hline $11 / 01 / 2008$ & 0,2341 & $0,0098 \pm 0,0023$ & 0,0097 & 24 & $0,0043-0,0159$ \\
\hline $31 / 01 / 2008$ & 0,3828 & $0,0142 \pm 0,0069$ & 0,0135 & 27 & $0,0042-0,0331$ \\
\hline $18 / 02 / 2008$ & 0,2962 & $0,0114 \pm 0,0039$ & 0,0118 & 26 & $0,0015-0,0179$ \\
\hline $29 / 02 / 2008$ & 0,2199 & $0,0085 \pm 0,0032$ & 0,0080 & 26 & $0,0022-0,0145$ \\
\hline $11 / 03 / 2008$ & 0,1361 & $0,0050 \pm 0,0023$ & 0,0049 & 27 & $0,0015-0,0104$ \\
\hline 01/04/2008 & 0,3900 & $0,0130 \pm 0,0054$ & 0,0126 & 30 & $0,0030-0,0292$ \\
\hline Total & 6,5623 & $0,2625 \pm 0,1400$ & 0,2312 & 705 & $0,0853-37,7180$ \\
\hline Total geral (sem exclusão de outliers) & 7,6767 & $0,3071( \pm 0,1508)$ & 0,3192 & 745 & $0,0926-0,6153$ \\
\hline
\end{tabular}

(como os solos, por exemplo) estejam em uma amplitude favorável. Considerando que as restingas são, geomorfologicamente, mais recentes do que a encosta, é provável que a Floresta de Restinga tenha se mantido diferenciada das Terras Baixas em decorrência do filtro ambiental representado pelas condições mais restritivas do solo. Assim, será que espécies indicadoras das Terras Baixas, como Mollinedia schottiana, não teriam condições de sobreviver e/ou de crescer no ambiente mais restritivo da Restinga? Questões como essa poderão ser investigadas futuramente.

Tanto a riqueza quanto a diversidade de espécies foram menores na Floresta de Restinga do que nas Terras Baixas. A diversidade (H') na Restinga foi semelhante à encontrada em outras florestas de restinga do Brasil (por exemplo, Ramos-Neto 1993, Silva et al. 1994, César \& Monteiro 1995). Nas Terras Baixas, a diversidade (H') foi consideravelmente maior que em outras áreas de Floresta Ombrófila de Terras Baixas no Brasil e sua riqueza foi, com algumas exceções, superior à de outras florestas de encosta do estado de São Paulo (cujos resultados são mostrados por Siqueira 1994 e Tabarelli \& Mantovani 1999).
Embora as causas da variação na diversidade não sejam plenamente conhecidas, basicamente duas correntes de pensamento vêm sendo desenvolvidas para explicar a coexistência de espécies: a de que esta ocorre por processos estocásticos (Hubbell 2001) e a de que fatores ambientais regulariam a composição e a riqueza de espécies (por exemplo, Leigh Junior et al. 2004). Dentre esses fatores ambientais, alguns poderiam atuar como filtros abióticos que impediriam o estabelecimento e/ou o posterior desenvolvimento de muitas espécies, levando a uma menor diversidade. Acredita-se ser esse o caso da Floresta de Restinga investigada no presente estudo. Diversas espécies poderiam ter sido eliminadas localmente, uma vez que os solos não seriam propícios ao seu estabelecimento e persistência. As diferenças nos padrões de dispersão e fenodinâmica observadas por Pedroni (2001) entre a Floresta de Restinga e as Terras Baixas ajudam a explicar a manutenção de composições florísticas tão distintas.

Ao contrário do esperado não houve diferenças significativas na biomassa viva entre a Floresta de Restinga e as Terras Baixas. A menor abundância de árvores grandes (> $30 \mathrm{~cm}$ DAP) devido a restrições 
Assis, M.A. et al.

Tabela 6. Produção de serapilheira para cada quinzena de coleta na Floresta das Terras Baixas, no Parque Estadual da Serra do Mar, Ubatuba, São Paulo, Brasil. Table 6. Litterfall production, sampled every fortnight, by the Lowland Forest at Núcleo Picinguaba/Serra do Mar State Park, Ubatuba, Sao Paulo, Brazil.

\begin{tabular}{|c|c|c|c|c|c|}
\hline $\begin{array}{c}\text { Data } \\
\text { de coleta }\end{array}$ & $\begin{array}{c}\text { Total } \\
\left(\text { t.ha' }{ }^{-1}\right)\end{array}$ & $\begin{array}{c}\text { Média } \pm \text { DP } \\
(\text { t.ha-1 })\end{array}$ & $\begin{array}{c}\text { Mediana } \\
\left(\mathbf{t}^{\prime h} \mathbf{a}^{-1}\right)\end{array}$ & $\begin{array}{c}\text { Número efetivo } \\
\text { de coletas }\end{array}$ & $\begin{array}{c}\text { Amplitude de } \\
\text { variação }\left(\text { t.ha }^{-1}\right)\end{array}$ \\
\hline $26 / 03 / 2007$ & 0,5465 & $0,0188 \pm 0,0069$ & 0,0182 & 29 & $0,0099-0,0304$ \\
\hline $19 / 04 / 2007$ & 0,2789 & $0,0103 \pm 0,0040$ & 0,0096 & 27 & $0,0048-0,0192$ \\
\hline $30 / 04 / 2007$ & 0,3850 & $0,0160 \pm 0,0086$ & 0,0140 & 24 & $0,0065-0,0389$ \\
\hline $15 / 05 / 2007$ & 0,4188 & $0,0140 \pm 0,0047$ & 0,0144 & 30 & $0,0044-0,0256$ \\
\hline $29 / 05 / 2007$ & 0,1808 & $0,0065 \pm 0,0026$ & 0,0058 & 28 & $0,0025-0,0134$ \\
\hline $14 / 06 / 2007$ & 0,2292 & $0,0092 \pm 0,0033$ & 0,0089 & 25 & $0,0049-0,0170$ \\
\hline $29 / 06 / 2007$ & 0,2042 & $0,0068 \pm 0,0036$ & 0,0056 & 30 & $0,0025-0,0140$ \\
\hline $13 / 07 / 2007$ & 0,0863 & $0,0033 \pm 0,0017$ & 0,0031 & 26 & $0,0009-0,0074$ \\
\hline $28 / 07 / 2007$ & 0,5053 & $0,0187 \pm 0,0080$ & 0,0177 & 27 & $0,0074-0,0340$ \\
\hline $15 / 08 / 2007$ & 0,1061 & $0,0039 \pm 0,0018$ & 0,0039 & 27 & $0,0015-0,0083$ \\
\hline $29 / 08 / 2007$ & 0,1295 & $0,0045 \pm 0,0021$ & 0,0040 & 29 & $0,0005-0,0100$ \\
\hline $17 / 09 / 2007$ & 0,1769 & $0,0061 \pm 0,0027$ & 0,0054 & 29 & $0,0008-0,0118$ \\
\hline $02 / 10 / 2007$ & 0,3692 & $0,0123 \pm 0,0064$ & 0,0102 & 30 & $0,0040-0,0277$ \\
\hline $15 / 10 / 2007$ & 0,1468 & $0,0052 \pm 0,0024$ & 0,0049 & 28 & $0,0015-0,0105$ \\
\hline $27 / 10 / 2007$ & 0,2902 & $0,0107 \pm 0,0041$ & 0,0103 & 27 & $0,0033-0,0205$ \\
\hline $15 / 11 / 2007$ & 0,7750 & $0,0267 \pm 0,0081$ & 0,0269 & 29 & $0,0127-0,0488$ \\
\hline $02 / 12 / 2007$ & 0,3434 & $0,0118 \pm 0,0050$ & 0,0116 & 29 & $0,0051-0,0232$ \\
\hline $15 / 12 / 2007$ & 0,2411 & $0,0089 \pm 0,0023$ & 0,0087 & 27 & $0,0033-0,0131$ \\
\hline $28 / 12 / 2007$ & 0,2279 & $0,0074 \pm 0,0030$ & 0,0061 & 31 & $0,0030-0,0140$ \\
\hline $11 / 01 / 2008$ & 0,4068 & $0,0131 \pm 0,0056$ & 0,0126 & 31 & $0,0057-0,0262$ \\
\hline $31 / 01 / 2008$ & 0,3609 & $0,0129 \pm 0,0053$ & 0,0126 & 28 & $0,0054-0,0235$ \\
\hline $18 / 02 / 2008$ & 0,2911 & $0,0100 \pm 0,0047$ & 0,0088 & 29 & $0,0032-0,0208$ \\
\hline $29 / 02 / 2008$ & 0,2693 & $0,0087 \pm 0,0040$ & 0,0074 & 31 & $0,0026-0,0182$ \\
\hline $11 / 03 / 2008$ & 0,1716 & $0,0057 \pm 0,0028$ & 0,0053 & 30 & $0,0013-0,0117$ \\
\hline $01 / 04 / 2008$ & 0,3683 & $0,0127 \pm 0,0049$ & 0,0122 & 29 & $0,0037-0,0228$ \\
\hline Total & 7,5091 & $0,3004 \pm 0,1558$ & 0,2789 & 710 & $0,0005-0,0488$ \\
\hline Total geral (sem excluir os outliers) & 8,7277 & $0,3491 \pm 0,1733$ & 0,3540 & 755 & $0,1430-0,9209$ \\
\hline
\end{tabular}

edáficas e ao possível efeito de perturbações passadas explicaria os valores mais baixos de biomassa na Restinga (Alves et al. 2010).

Ao contrário de Moraes et al. (1999) na Ilha do Cardoso, que encontraram uma produção de serapilheira de 3,9 t.ha ${ }^{-1} / \mathrm{ano}^{-1}$ numa floresta de encosta e de 6,3 t.ha ${ }^{-1} / \mathrm{ano}^{-1}$ numa Floresta de Restinga, nossos resultados não mostram diferenças significativas entre a Restinga e as Terras Baixas. Os valores encontrados foram maiores que os de Moraes et al. (1999) e também que os de Pires et al. (2006), que encontraram uma produção de $5,1 \mathrm{t}^{\mathrm{ha}} \mathrm{ha}^{-1} / \mathrm{ano}^{-1}$ numa Floresta de Restinga na Ilha do Mel, e somente foram consideravelmente inferiores aos de alguns estudos efetuados na Floresta Amazônica (Pires et al. 2006).

A análise de similaridade com outros levantamentos realizados em florestas de restinga e de encosta da Mata Atlântica não indicou agrupamentos consistentes, tendo em vista que a similaridade foi muito baixa em geral - o grupo mais forte, formado por duas áreas de encosta do Rio de Janeiro, não chegou a apresentar 50\% de similaridade de Jaccard. A baixa similaridade florística entre as florestas de Ubatuba aqui investigadas e as outras florestas já estudadas reforça a ideia de uma grande heterogeneidade da Planície Costeira nas regiões Sudeste e Sul do Brasil.

Concluindo, a Floresta de Restinga e a Floresta das Terras Baixas investigadas são constituídas por espécies arbóreas diferentes e apresentam apenas poucas espécies em comum, que em sua maioria são generalistas e ubíquas. A diferença em composição pode ser determinada pelas características físico-químicas dos respectivos solos, oriundos de processos pedogênicos distintos. A forte pressão de seleção exercida pela saturação hídrica do solo, que dura de três a cinco meses por ano na Restinga, pode explicar a menor diversidade florística da Floresta de Restinga. Entretanto, apesar das grandes diferenças de composição e estrutura, as duas comunidades apresentaram valores semelhantes nos indicadores funcionais (biomassa e produção de serapilheira). Embora as condições edáficas mostrem-se distintas, cada espécie responderia de modo particular a essas variações ambientais e, ao encontrar um espectro favorável de condições e recursos, não haveria uma limitação diferencial à produção de biomassa e de serapilheira. 


\section{Agradecimentos}

Este trabalho foi financiado pela Fundação de Amparo à Pesquisa do Estado de São Paulo (FAPESP) no âmbito do Projeto Temático Gradiente Funcional - "Composição florística, estrutura e funcionamento da Floresta Ombrófila Densa dos Núcleos Picinguaba e Santa Virgínia do Parque Estadual da Serra do Mar" (Processo 03/12595-7), que faz parte do Programa BIOTA/FAPESP - O Instituto Virtual da Biodiversidade (www.biota.org.br). Aos Programas de Pós-Graduação do IB/UNICAMP, do CENA/USP e do IB/UNESP- - Rio Claro envolvidos nesse Projeto Temático; à FAPESP, CAPES e ao CNPq pelas bolsas concedidas; aos demais pesquisadores da equipe do BIOTA Gradiente Funcional pela ajuda nos trabalhos de campo, pelas inúmeras discussões estimulantes e pelo excelente convívio nesses cinco anos. Autorização COTEC/IF 41.065/2005 e autorização IBAMA/CGEN 093/2005.

\section{Referências Bilbiográficas}

ACKERLY, D.D. 2003. Community assembly, niche conservatism, and adaptive evolution in changing environments. Int. J. Plant Sci. 164(3 Suppl):165-184. http://dx.doi.org/10.1086/368401

ALVES, L.F., VIEIRA, S.A., SCARANELLO, M.A., CAMARGO, P.B., SANTOS, F.A.M., JOLY, C.A. \& MARTINELLI, L.A. 2010 Forest structure and live aboveground biomass variation along an elevational gradient of tropical Atlantic moist forest (Brazil). Forest Ecol. Manag. 260:679-691. http://dx.doi.org/10.1016/j.foreco.2010.05.023

ANGIOSPERM PHYLOGENY GROUP - APG II. 2003. An update of the Angiosperm Phylogeny Group classification for the orders and families of flowering plants: APG II. Bot. J. Lin. Soc. 141:399-436. http://dx.doi. org/10.1046/j.1095-8339.2003.t01-1-00158.x

ARAÚJO, D.S.D. \& LACERDA, L.D. 1987. A natureza das restingas. Ciência Hoje 6(32):42-48.

ASSIS, A.M., PEREIRA, O.J. \& THOMAZ, L.D. 2004. Fitossociologia de uma floresta de restinga no Parque Estadual Paulo César Vinha, Setiba, município de Guarapari (ES). Rev.bras.bot. 27(2):349-361.

AYRES, M., AYRES JÚNIOR, M., AYRES, D.L. \& SANTOS, A.A. 2007. BIOESTAT - Aplicações estatísticas nas áreas das ciências biomédicas. Ong Mamiraua, Belém.

BROWN, J.H. \& LOMOLINO, M.V. 2006. Biogeografia. 2nd ed. FUNPEC, Ribeirão Preto.

BRUNIG, E.F. 1983. Vegetation structure and growth. In Tropical rain forest ecosystems: structure and function (F.B. Golley). Elsevier Scientific Publishing Company, Amsterdam, p. 49-75.

CÉSAR, O. \& MONTEIRO, R. 1995. Florística e fitossociologia de uma floresta de restinga em Picinguaba (Parque Estadual da Serra do Mar), Município de Ubatuba - SP. Naturalia 20:89-105.

CHAVE, J., RIERA, B. \& DUBOIS, M.-A. 2001. Estimation of Biomass in a Neotropical Forest of French Guiana: Spatial and Temporal Variability. J. Trop. Ecol. 17(1):79-96. http://dx.doi.org/10.1017/S0266467401001055

CHAVE, J., ANDALO, C., BROWN, S., CAIRNS, M., CHAMBERS, J.C., EAMUS, D., FÖLSTER, H., FROMARD, F., HIGUCHI, N., KIRA, T., LESCURE, J., NELSON, B.W., OGAWA, H., PUIG, H., RIÉRA, B. \& YAMAKURA, T. 2005. Tree allometry and improved estimation of carbon stocks and balance in tropical forests. Oecologia 145:87-99. http://dx.doi.org/10.1007/s00442-005-0100-x

CLARK, D.A. 2002. Are tropical forests an important carbon sink? Reanalysis of the long-term plot data. Ecol. Appl. 12:3-7. http://dx.doi. org/10.1890/1051-0761(2002)012[0003:ATFAIC]2.0.CO;2

COLWELL, R.K. 2009. EstimateS: Statistical Estimation of species richness and shared species from samples. Version 8.2. purl.oclc.org/estimates
CORRÊA, A.C.B., SILVA, D.G. \& MELO, J.S. 2008. Utilização de depósitos de encostas dos brejos pernambucanos como marcadores paleoclimáticos do quaternário tardio no semi-árido nordestino. Mercator - Revista de Geografia da UFC 14(7):99-125.

DENSLOW, J.S. 1987. Tropical rainforest gaps and tree species diversity. Ann. Rev. Ecol. Syst. 18:431-451. http://dx.doi.org/10.1146/annurev. es.18.110187.002243

EISENLOHR, P.V., MELO, M.M.R.F., IVANAUSKAS, N.M., SOUZA, V.C., RODRIGUES, R.R., DUARTE, A.R., BREIR, T.B. \& UDULUTSCH, R.G. 2011. Floresta Ombrófila Densa Atlântica: bases conceituais e estudo de caso no Parque Estadual Carlos Botelho, SP, Brasil. In Fitossociologia no Brasil: Métodos e Estudos de Caso (J.M. Felfili, P.V. Eisenlohr, M.M.R.F. Melo, L.A. Andrade \& J.A.A. MeiraNeto, orgs.). Editora UFV, Viçosa. No prelo.

FACELLI, J.M. \& PICKETT, S.T.A. 1991. Plant Litter: its dynamics and effects on plant community structure. Bot. Rev. 57(1):1-32. http://dx.doi. org/10.1007/BF02858763

FELFILI, J.M. \& REZENDE, R.P. 2003. Conceitos e Métodos em Fitossociologia. Universidade de Brasília, Faculdade de Tecnologia, Brasília. Comunicações Técnicas Florestais, v. 5.

Gauch Jr., H.G. 1982. Multivariate analysis in community ecology. Cambridge Studies in Ecology, Cambridge.

GUERRA, A.T. \& GUERRA, A.J.T. 1997. Novo dicionário geológicogeomorfológico. Bertrand Brasil, Rio de Janeiro.

GUILHERME, F.A.G., MORELLATO, L.P.C. \& ASSIS, M.A. 2004. Horizontal and vertical tree community structure in a lowland Atlantic Rain Forest, Southeastern Brazil. Rev. bras. bot. 27(4):725-737.

HAMMER, Ø., HARPER, D.A.T. \& RYAN, P.D. 2001. PAST: Paleontological Statistics package for education and data analysis. Palaeontol. Electron. 4(1).

HILL, M.O. 1979. TWINSPAN - a FORTRAN program for arranging multivariate data in an ordered two-way table by classification of individuals and attributes. Cornell University, Ithaca, New York.

HILL, M. \& SMILAUER, P. 2005. TWINSPAN for Windows, version 2.3.

HUBBELL, S.P. 2001. The unified neutral theory of biodiversity and biogeography. Princeton University Press, Princeton, New Jersey.

JOLY, C.A., MARTinelli, L.A., ALVES, L.F., VIEIRA, S.A., TAMASHIRO, J.Y., AIDAR, M.P.M., CAMARGO, P.B., ASSIS, M.A., BERNACCI, L.C. \& DURIGAN, G. 2008. As parcelas permanentes do Projeto Temático BIOTA Gradiente Funcional: Composição florística, estrutura e funcionamento da Floresta Ombrófila Densa dos Núcleos Picinguaba e Santa Virgínia do Parque Estadual da Serra do Mar, São Paulo, Brasil. In Experiências de monitoramento no bioma Mata Atlântica com uso de parcelas permanentes. (C.R. Sanquetta, org.). RedeMAP: Rede de Parcelas Permanentes dos Biomas Mata Atlântica e Pampa \& Funpar (Fundação Universidade do Paraná), Curitiba, p. 109-148.

LACERDA, M.S. 2001. Composição florística e estrutura da comunidade arbórea num gradiente altitudinal da Mata Atlântica. Tese de Doutorado, Universidade Estadual de Campinas, Campinas.

LEÃO, Z.M.A.N. \& DOMINGUEZ, J.M.L. 2000. Tropical coast of Brazil. Mar. Poll. Bull. 41:112-122. http://dx.doi.org/10.1016/S0025326X(00)00105-3

LEIGH JUNIOR, E.G., DAVIDAR, P., DICK, C.W., PUYRAVAUD, J-P., TERBORGH, J., TER STEEGE, H. \& WRIGHT S.J. 2004. Why do some Tropical Forests have so many species of trees? Biotropica 36:447-473.

LEINZ, V. \& LEONARDOS, O.H. 1977. Glossário geológico. Editora Nacional, São Paulo.

LONDSDALE, W.M. 1988. Predicting the amout of litterfall in forests of the world. Ann. Bot. 61:319-324.

MALHI, Y., BALDOCCHI, D.D. \& JARVIS, P.G. 1999. The carbon balance of tropical, temperate and boreal forests. Plant Cell Environ 22(6):715740. http://dx.doi.org/10.1046/j.1365-3040.1999.00453.x 
MANTOVANI, M., RUSCHEL, A.R., PUCHALSKI, A., SILVA, J.Z., REIS, M.S. \& NODARI, R.O. 2005. Diversidade de espécies e estrutura sucessional de uma formação secundária da floresta ombrófila densa. Sci. For. 67:14-26.

MARTINS, S.C. 2010. Caracterização dos solos e serapilheira ao longo do gradiente altitudinal da Mata Atlântica, estado de São Paulo. Tese de Doutorado, Universidade de São Paulo, Piracicaba.

McCUNE, B. \& GRACE, J.B. 2002. Analysis of Ecological Communities. MjM Software, Gleneden Beach.

McCUNE, B. \& MEFFORD, M.J. 1999. PC-ORD - multivariate analysis of ecological data. Version 4.0. MjM Software Design, Gleneden Beach.

MELO, M.M.R.F. \& MANTOVANI, W. 1994. Composição florística e estrutura de trecho de Mata Atlântica de encosta na Ilha do Cardoso (Cananéia, SP, Brasil). Bol. Inst. Bot. 9:107-158.

MISSOURI BOTANICAL GARDEN - MOBOT. 2008. Missouri Botanical Garden Plant Science. Database - W3 TRÓPICOS. http://www.mobot. org (acesso contínuo em 2008 e 2009).

MORAES, R.M., DELITTI, W.B.C. \& STRUFFALDI-DE-VUONO, Y 1999. Litterfall and litter nutrient content in two Brazilian Tropical Forests. Rev.Bras.Bot. 22(1):9-16. http://dx.doi.org/10.1590/S010084041999000100002

MYERS, N., MITTERMEIER, R.A., MITTERMEIER, C.G., FONSECA, G.A.B. \& KENT, J. 2000. Biodiversity hotspots for conservation priorities. Nature 403:853-858. http://dx.doi.org/10.1038/35002501

NASCIMENTO, H.E.M. \& LAURANCE, W.F. 2002. Total aboveground biomass in central Amazonian rainforests: a landscape-scale study. Forest Ecol Manag 168(1-3):311-321. http://dx.doi.org/10.1016/S03781127(01)00749-6

OLIVEIRA, V.C. \& JOLY, C.A. 2010. Flooding tolerance of Calophyllum brasiliense Camb. (Clusiaceae): morphological, physiological and growth responses. Trees 24:185-193. http://dx.doi. org/10.1007/s00468-009-0392-2

OLMOS, I.L.J. \& CAMARGO, M.N. 1976. Ocorrência de alumínio tóxico nos solos do Brasil, sua caracterização e distribuição. Cienc. Cult. 28(2):171-180.

PEDRONI, F. 2001. Aspectos da estrutura e dinâmica da comunidade arbórea na Mata Atlântica de planície e encosta em Picinguaba, Ubatuba, SP. Tese de Doutorado, Universidade Estadual de Campinas, Campinas.

PESSOA, S.V.A. \& OLIVEIRA, R.R. 2006. Análise estrutural da vegetação arbórea em três fragmentos florestais na Reserva Biológica de Poço das Antas, Rio de Janeiro, Brasil. Rodriguésia 57:391-412.

PHILLIPS, O.L. \& BAKER, T. 2002. RAINFOR - Field manual for plot establishment and remeasurement. http://www.geog.leeds.ac.uk/projects/ rainfor/ (ultimo acesso em 05/2006).

PIRES, L.A., BRITEZ, R.M., MARTEL, G. \& PAGANO, S.N. 2006. Produção, acúmulo e decomposição da serapilheira em uma restinga da Ilha do Mel, Paranaguá, PR, Brasil. Acta bot.bras. 20(1):173-184.

PONÇANO, W.L., CARNEIRO, C.D.R., BISTRICHI, C.A., ALMEIDA, F.F.M. \& PRANDINI, F.L. 1981. Mapa Geomorfológico do estado de São Paulo. Instituto de Pesquisas Tecnológicas do Estado de São Paulo, São Paulo, v. 1.

POOLE, R.W. 1974. An introduction to quantitative ecology. McGraw-Hill, New York.

RAMOS-NETO, M.B. 1993. Análise florística e estrutural de duas florestas sobre a restinga, Iguape, São Paulo. Dissertação de Mestrado, Universidade de São Paulo, São Paulo.

RIZZINI, C.T. 1997. Tratado de Fitogeografia do Brasil. Aspectos ecológicos, sociológicos e florísticos. Âmbito Cultural Edições Ltda., Rio de Janeiro.

SACRAMENTO, A.C., ZICKEL, C.S. \& ALMEIDA JUNIOR, E.B. 2007. Aspectos florísticos da vegetação de Restinga no litoral de Pernambuco. Rev. Arvore 31(6):1121-1130. http://dx.doi.org/10.1590/S010067622007000600017
SCHERER, A., MARASCHIN-SILVA, F. \& BAPTISTA, L.R.M. 2005. Florística e estrutura do componente arbóreo de matas de Restinga arenosa no Parque Estadual de Itapuã, RS, Brasil. Acta bot.bras. 19(4):717-726.

SCUDELLER, V.V., MARTINS, F.R. \& SHEPHERD, G.J. 2001. Distribution and abundance of arboreal species in the atlantic ombrophilous dense forest in Southeastern Brazil. Plant Ecol. 152: 185-199. http://dx.doi. org/10.1023/A:1011494228661

SCUDELLER, V.V. 2002. Análise Fitogeográfica da Mata Atlântica - Brasil. Tese de Doutorado, Universidade Estadual de Campinas, Campinas.

SHEPHERD, G.J. 2008. Fitopac 2. Versão preliminar. Departamento de Botânica, Universidade Estadual de Campinas, Campinas.

SILVA, S.M., BRITEZ, R.M., SOUZA, W.S. \& JOLY, C.A. 1994. Fitossociologia do componente arbóreo da floresta de restinga da Ilha do Mel, Paranaguá, PR. In III Simpósio de Ecossistemas da Costa Sul e Sudeste Brasileira (S. Watanabe, coord.). Aciesp, São Paulo, p.33-48.

SILVA, A.F. \& LEITÃO-FILHO, H.F. 1982. Composição florística e estrutura de um trecho da mata atlântica de encosta no município de Ubatuba (São Paulo, Brasil). Rev. Bras. Bot. 5:43-52.

SIQUEIRA, M.F. 1994. Classificação da vegetação e ordenação de espécies arbóreas da Mata Atlântica. Dissertação de Mestrado, Universidade Estadual de Campinas, Campinas.

SMITH, A.R., PRYER, K.M., SCHETTPELZ, E., KORALL, P., SCHEIDER, H. \& WOLF, P. 2006. A classification for extant ferns. Taxon 55:705-731. http://dx.doi.org/10.2307/25065646

SMITH, E.P. \& van BELLE, G. 1984. Nonparametric estimation of species richness. Biometrics 40:119-129. http://dx.doi.org/10.2307/2530750

SNEATH, P.H. \& SOKAL, R.R. 1973. Numerical taxonomy. Freeman and Company, San Francisco.

SOUSA NETO, E., CARMO, J.B., KELLER, M., MARTINS, S.C., ALVES, L.F., VIEIRA, S.A., PICCOLO, M.C., CAMARGO, P., COUTO, H.T.Z., JOLY, C.A. \& MARTINELLI, L.A. 2011. Soil-atmosphere exchange of nitrous oxide, methane and carbon dioxide in a gradient of elevation in the coastal Brazilian Atlantic Forest. Biogeosciences 8: 733-742.

SPAIN, A.V. 1984. Litterfall and the Standing Crop of Litter in Three Tropical Australian Rainforests. J. Ecol. 72(3):947-961. http://dx.doi. org/10.2307/2259543

SUNDARAPADIAN, S.M. \& SWAMY, P.S. 1999. Litter production and leaf-litter decomposition of selected tree species in tropical forests at Kodayar in the Western Ghats, India. For. Ecol. Manag. 123:231-244. http://dx.doi.org/10.1016/S0378-1127(99)00062-6

SZTUTMAN, M. \& RODRIGUES, R.R. 2002. O mosaico vegetacional numa área de floresta contínua de planície litorânea, Parque Estadual da Campina do Encantado, Pariquera-Açu, SP. Rev. Bras. Bot. 25:161-176. http://dx.doi.org/10.1590/S0100-84042002000200005

TABARELLI, M. \& MANTOVANI, W. 1999. A riqueza de espécies arbóreas na floresta atlântica de encosta no estado de São Paulo (Brasil). Rev. Bras. Bot. 22(2):1-12.

TECCHIO, M.A., PAIOLI-PIRES, E.J., GRASSI FILHO, H., BRIZOLA, R.M.O., VIEIRA, C.R.Y. \& TERRA, M.M. 2005. Avaliação de variáveis fisiológicas em porta-enxertos de videira cultivados em solução nutritiva com a adição de alumínio. Cienc. Agrotec. 29(2):274-283. http://dx.doi. org/10.1590/S1413-70542005000200002

TIEPOLO, G., CALMON, M. \& FERETTI, A.R. 2002. Measuring and Monitoring Carbon Stocks at the Guaraqueçaba Climate Action Project, Paraná, Brazil. In International Symposium on Forest Carbon Sequestration and Monitoring. Extension Serie Taiwan Forestry Research Institute, v. 153, p. 98-115.

VALENTIN, J.L. 2000. Ecologia Numérica: uma introdução à análise multivariada de dados ecológicos. Interciência, Rio de Janeiro.

VELOSO, H.P., RANGEL FILHO, A.L.R. \& LIMA, J.C.A. 1991. Classificação da vegetação brasileira, adaptada a um sistema universal. IBGE, Rio de Janeiro

VIEIRA, L.S. 1988. Manual de Ciência do Solo. Ed. Agronômica Ceres, São Paulo. 
VIEIRA, S.A., ALVES, L.F., AIDAR, M., ARAÚJO, L.S., BAKER, T., BATISTA, J.L.F., CAMPOS, M.C., CAMARGO, P.B., CHAVE, J., DELITTI, W.B.C., HIGUCHI, N., HONORIO, E., JOLY, C.A., KELLER, M., MARTINELLI, L.A., MATTOS, E.A., METZKER, T., PHILLIPS, O., SANTOS, F.A.M., SHIMABUKURO, M.T., SILVEIRA, M. \& TRUMBORE, S.E. 2008. Estimation of biomass and carbon stocks: the case of the Atlantic Forest. Biota Neotropica 8(2): http://www. biotaneotropica.org.br/v8n2/pt/abstract?point-of-view+bn00108022008 http://dx.doi.org/10.1590/S1676-06032008000200001
VILLWOCK, J.A. 1987. Processos costeiros e a formação das praias arenosas e campos de dunas ao longo da costa sul e sudeste brasileira. In Simpósio de Ecossistemas da Costa Sul e Sudeste Brasileira. ACIESP, Águas de Lindóia. pp.380-398.

VITOUSEK, P.M. 1982. Nutrient cycling and nutrient use efficiency. Am. Nat. 119(4):53-72. http://dx.doi.org/10.1086/283931

ZAR, J.H. 1999. Biostatistical analysis. 4nd ed. Prentice-Hall, Inc., New Jersey. FUNPEC,o. 2011.nsEdo. pp. 372-387)n \&nn.

Recebido em 01/04/2011

Versão reformulada recebida em 01/05/2011

Publicado em 16/05/2011 